Revue des patrimoines

$28 \mid 2016$

Le moulage. Pratiques historiques et regards contemporains

\title{
Gypsothèque du musée du Louvre. Les apports de la restauration à la datation des tirages en plâtre anciens
}

The gypsothèque of the Louvre museum. How restoration brings new

information about old plaster casts

\section{Élisabeth Le Breton}

\section{(2) OpenEdition}

Journals

Édition électronique

URL : http://journals.openedition.org/insitu/12581

DOI : 10.4000/insitu.12581

ISSN : 1630-7305

Éditeur

Ministère de la culture

\section{Référence électronique}

Élisabeth Le Breton, « Gypsothèque du musée du Louvre. Les apports de la restauration à la datation des tirages en plâtre anciens », In Situ [En ligne], 28 | 2016, mis en ligne le 10 mars 2016, consulté le 30 avril 2019. URL : http://journals.openedition.org/insitu/12581 ; DOI : 10.4000/insitu. 12581

Ce document a été généré automatiquement le 30 avril 2019.

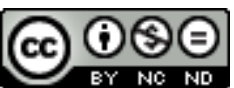

In Situ Revues des patrimoines est mis à disposition selon les termes de la licence Creative Commons Attribution - Pas d'Utilisation Commerciale - Pas de Modification 4.0 International. 


\title{
Gypsothèque du musée du Louvre. Les apports de la restauration à la datation des tirages en plâtre anciens
}

\author{
The gypsothèque of the Louvre museum. How restoration brings new \\ information about old plaster casts
}

Élisabeth Le Breton

Communication présentée lors des journées d'étude « Le moulage. Pratiques historiques et regards contemporains » organisées par la Cité de l'architecture et du patrimoine et le musée du quai Branly, les 14 et 15 novembre 2012.

Destiné initialement à constituer le socle d'un "musée des Monuments antiques", l'ensemble des tirages ${ }^{1}$ en plâtre d'après l'antique, déplacé et conservé entre 1970 et $1973^{2}$ dans les écuries du roi bâties par Jules Hardouin-Mansart à Versailles, est affecté au musée du Louvre en $2001^{3}$.

2 Depuis, placée sous la responsabilité du département des Antiquités grecques, étrusques et romaines, cette collection, connue désormais sous le nom de "gypsothèque », est en cours de réhabilitation. En effet, après avoir connu de multiples déménagements, puis une forme d'abandon dont témoignent encore les stigmates visibles sur une grande partie des œuvres, l'ensemble, riche de près de 5000 œuvres, exige d'importantes campagnes de restauration. Ces dernières ont débuté à partir de 2004, et ont été consacrées, en priorité, aux œuvres les plus structurellement endommagées. Après huit ans de travaux soutenus, les séquelles s'atténuent, 91 tirages ont été restaurés et les œuvres commencent à livrer leur histoire.

3 En France, cette histoire plonge ses racines dans les collections royales des $\mathrm{XVI}^{\mathrm{e}}$ et $\mathrm{XVII}^{\mathrm{e}}$ siècles et se prolonge amplement jusqu'au XIX ${ }^{e}$. Dans les études publiées entre 1970 et 2000 , il était assez convenu que la gypsothèque abritait une majorité de pièces du XIX 
siècle et peu des temps anciens : deux du XVII siècle, le tirage de l'Hercule Farnèse du musée de Naples et celui de Commode en Hercule des musées du Vatican à Rome et une, du XVIII ${ }^{e}$ siècle, le tirage du Gaulois mourant du musée du Capitole à Rome.

Mais comment être assurés que nous soyons héritiers d'œuvres aussi anciennes?

Ces trois pièces ont été transférées à Versailles depuis les collections de l'École nationale des beaux-arts de Paris. Dépositaire par sa constitution de ce qui avait subsisté des collections royales et de l'Académie royale de peinture et de sculpture, il était en effet vraisemblable que le musée du Louvre, suite à l'affectation, ait pu hériter de tirages ayant appartenu à ces collections. Seulement si la datation proposée reposait sur des documents d'archives, elle était encore solidement étayée par une certaine forme de tradition.

Les outils documentaires que sont les archives, les inventaires, les descriptions de salles, les guides de voyages, ou encore les représentations diverses, peintures ou dessins, demeurent essentiels, mais en matière de moulages et de jets, ils se révèlent très insuffisants et il n'est pas possible de les retenir comme éléments déterminants (fig. 1).

Figure 1

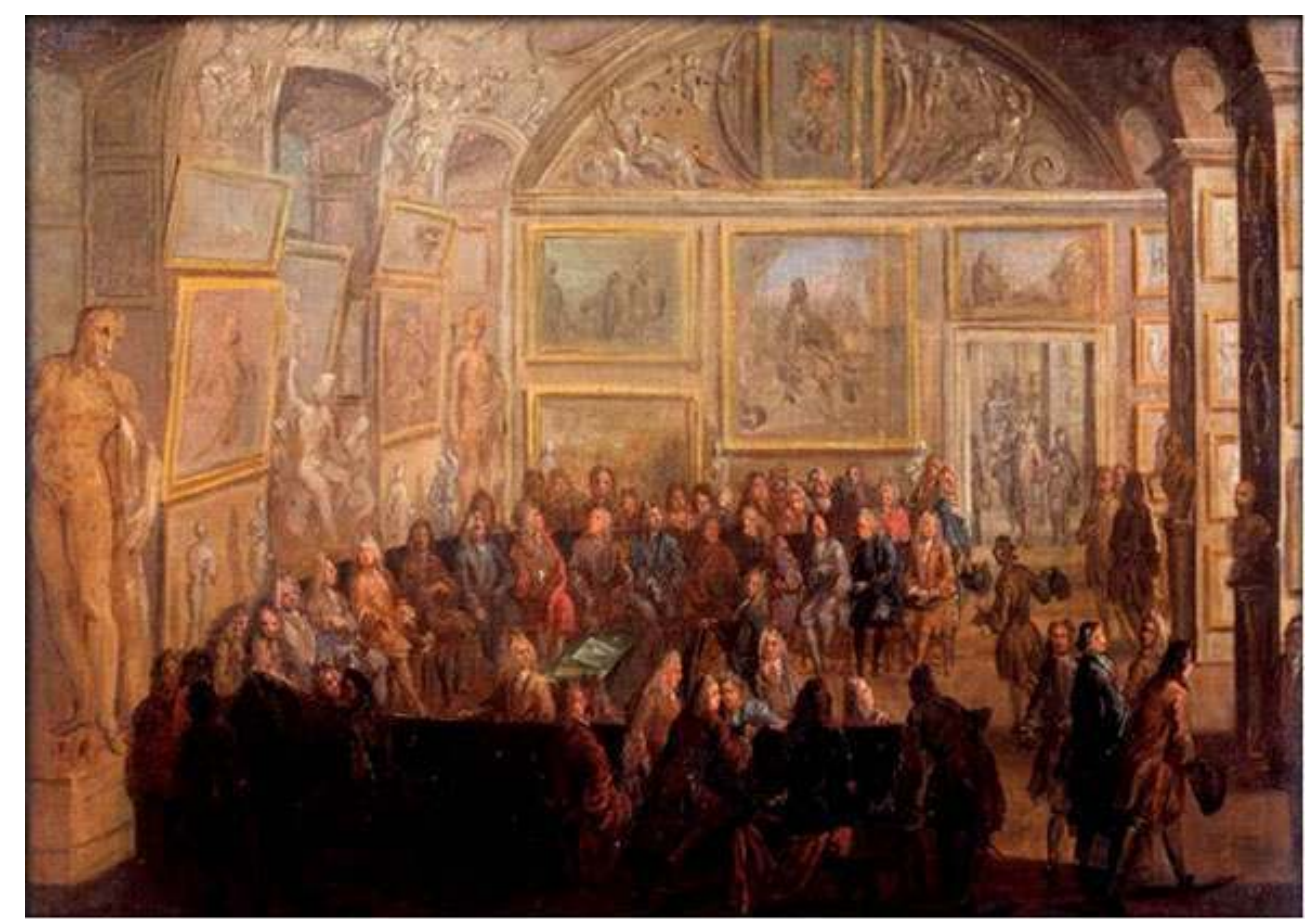

Vue d'une salle de l'Académie royale de peinture et de sculpture au Louvre - Salle des séances ordinaires (aujourd'hui salle de Diane). Jean-Baptiste Martin (1659-1735), Département des peintures, musée du Louvre - R.F 1998.36. À gauche, on distingue les grands tirages en plâtre de l'Hercule et de la Flore Farnèse de part et d'autre du Laocoon du Vatican. N photo RMN 2000 - 00 DN 13163.

(c) Musée du Louvre.

\section{Le goût pour les grandes références antiques romaines}

7 Les modèles recherchés à la fin $\mathrm{du} \mathrm{XVII}^{\mathrm{e}}$ et au début du XVIII ${ }^{\mathrm{e}}$ siècle sont parfaitement connus. Dominés par la statuaire et les grandes références antiques romaines, à quelques exceptions près, ils sont toujours dans la gypsothèque. Mais identifier un modèle n'est pas 
concluant. À partir d'une prise d'empreinte, à l'estampage à la terre ou en plâtre, plusieurs tirages peuvent être déclinés; d'un moule à la terre, dans les meilleurs des moules, deux et peut-être jusqu'à trois tirages et d'un moule à pièces en plâtre, davantage, presque à l'envi et jusqu'à l'usure du moule. Ils peuvent être facilement déplacés, restaurés à différentes reprises si nécessaire, mais encore surmoulés ${ }^{4}$; ils ne sont jamais signés. Par ailleurs, dans un même lieu, plusieurs exemplaires d'un même modèle peuvent cohabiter (fig. 2). Nous nous heurtons ainsi à cette difficulté majeure de la datation des tirages en plâtre.

Figure 2

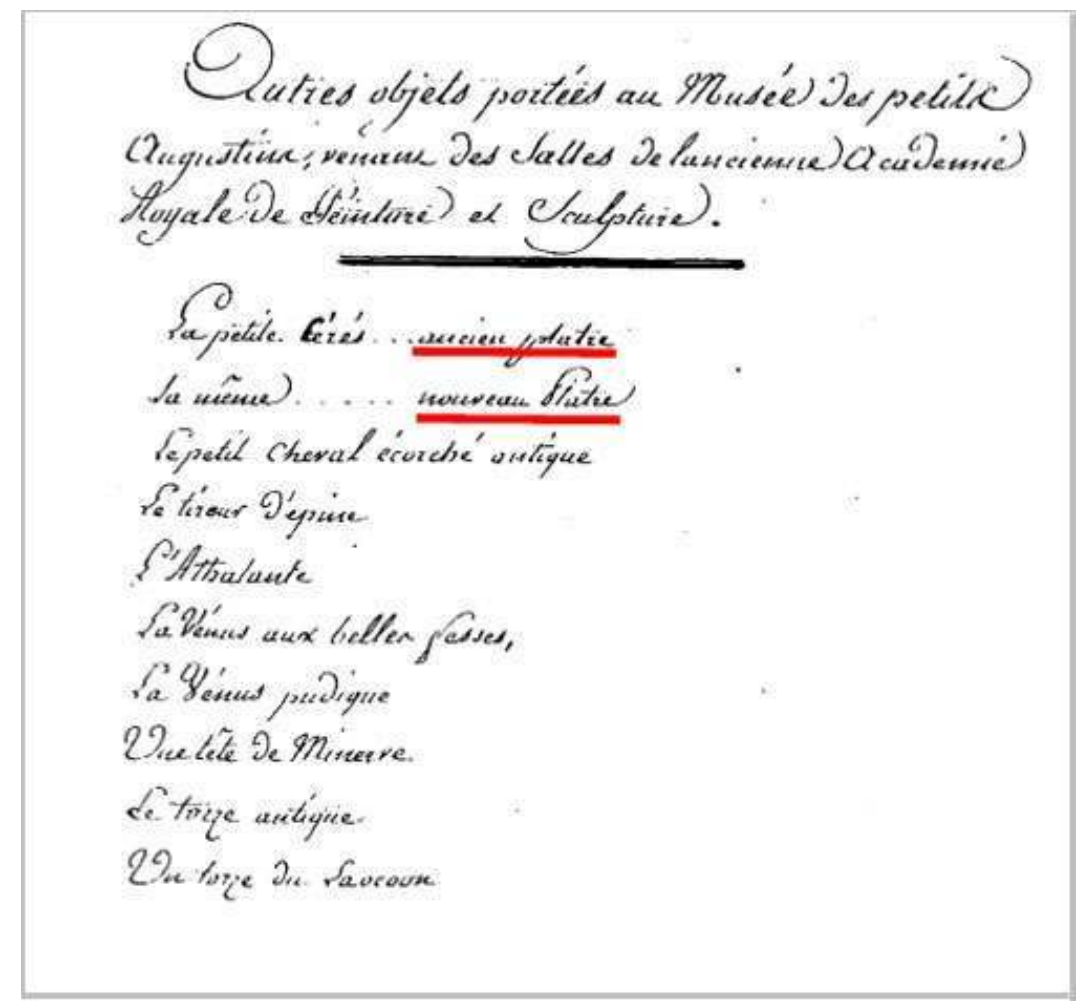

A.N AJ 52453 - 1er juin 1817. Liste partielle d'objets montrant que plusieurs tirages d'un même modèle peuvent cohabiter et qu'ils peuvent avoir été réalisés à différents moments.

Phot. Le Breton, É., 2012. @ Musée du Louvre.

De quels moyens alors pouvons-nous disposer pour identifier et dater de manière indiscutable des pièces aussi anciennes?

\section{Les campagnes de restauration}

Quand commencèrent les premières campagnes de restauration fondamentale, notre intérêt porta, en priorité, sur les œuvres présentant des désordres structurels sévères ; il s'agissait précisément des tirages conventionnellement désignés comme les plus anciens. 


\section{Un sauvetage inespéré : le Gaulois mourant}

10 Le tirage du Gaulois mourant (fig. 3) du Capitole pour lequel nous connaissions un exemplaire dans les collections royales et dans celles de l'Académie royale de peinture et de sculpture ${ }^{5}$ fut le premier restauré ${ }^{6}$ et donc, celui à partir duquel nous avons commencé à collecter des données pour tenter de brosser le portrait d'un « vieux plastre ».

Figure 3

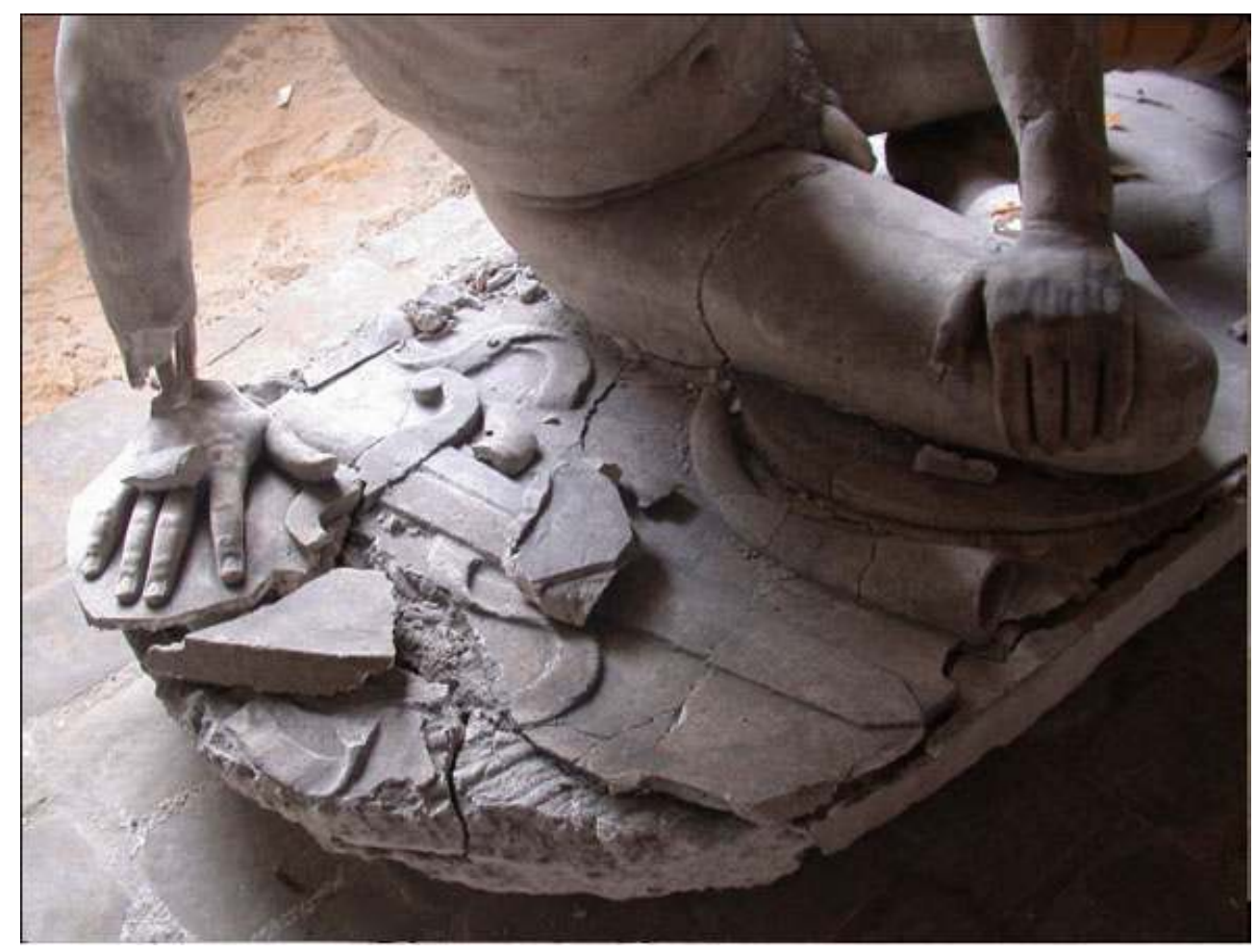

Le tirage du Gaulois mourant. Détail de la terrasse avant restauration.

Phot. Roumégoux, P. ㄷ Musée du Louvre.

11 Nous avons observé, en cours de restauration, la technique de mise en forme et les matériaux utilisés, susceptibles de révéler des caractéristiques. Nous avons regardé spécifiquement ce que l'on peut en apprendre, concernant le moule, puis le tirage, et finalement le matériau constitutif, le « plâtre ». 
Figure 4

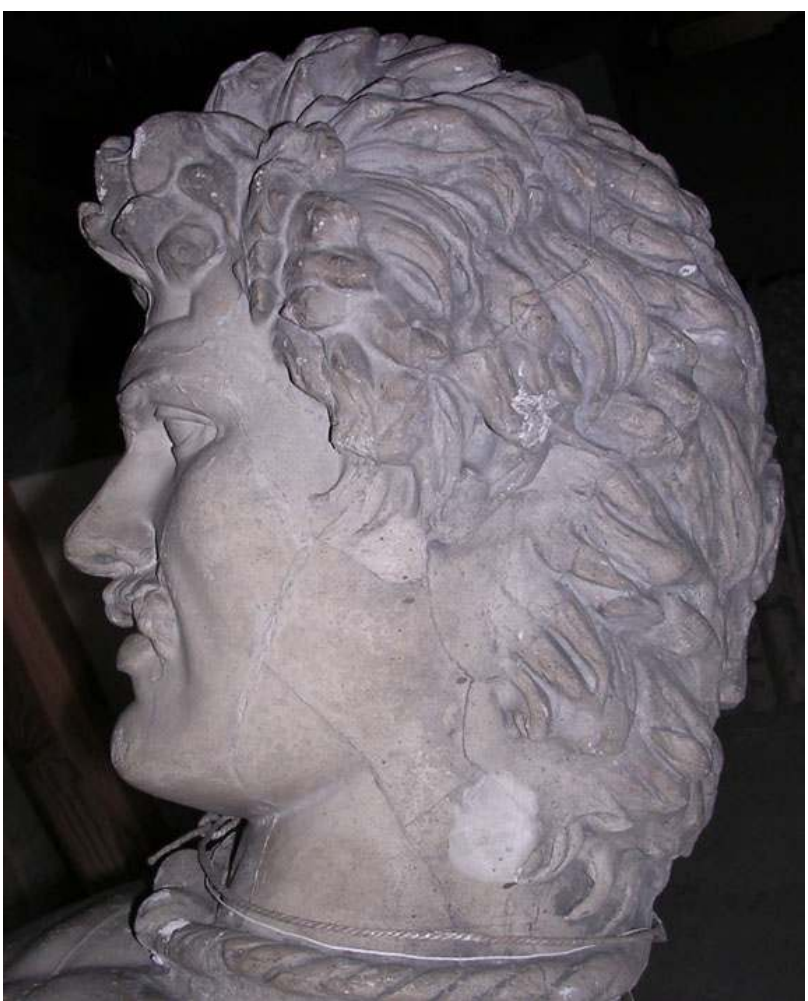

Le tirage du Gaulois mourant. Traces du réseau de coutures en surface du tirage, au niveau du visage et de la tête.

Phot. Roumégoux, P. @ C Musée du Louvre. 
Figure 5

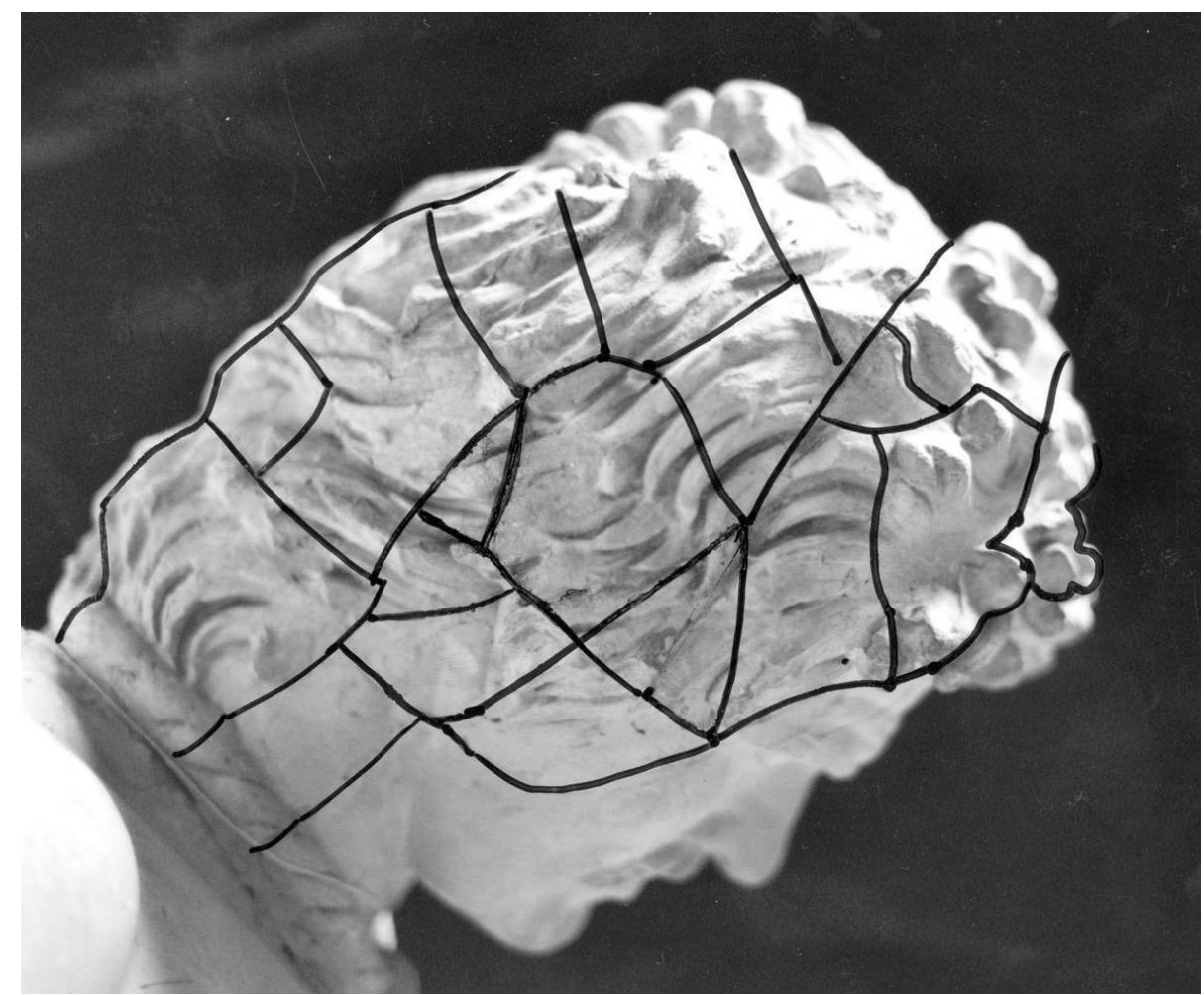

Le tirage du Gaulois mourant. Traces du réseau de coutures en surface du tirage, au niveau du visage et de la tête.

Phot. Roumégoux, P. ㄷ Musée du Louvre.

12 La technique de prise d'empreinte utilisée, telle qu'elle apparaît à la surface du tirage, a été celle d'un moule à pièces en terre. En effet, les marques des pièces apparaissent en très grand nombre, de petites dimensions, aux angles souvent pointus; elles révèlent un réseau de coutures particulières, courtes, très larges, aux crêtes comme écrasées, ce qui confirme l'usage de pièces fabriquées en terre crue et travaillées à l'estampage (fig. 4, fig. 5). Du fait des contraintes liées à la rétractation de la terre, on constate aussi parfois, à la surface de légers décalages de pièces (fig. 6), comme des petits affaissements, tout à fait caractéristiques de l'usage de ces moules. Ce réseau, formes, lignes, crêtes et décalages de pièces, est ainsi très éloigné de celui que l'on observe sur des tirages plus récents, où les empreintes montrent l'utilisation de pièces découpées plutôt grandes, à angles droits, parfaitement jointives et laissant visible en surface un réseau très fin de crêtes aux arêtes acérées (fig. 7). 
Figure 6

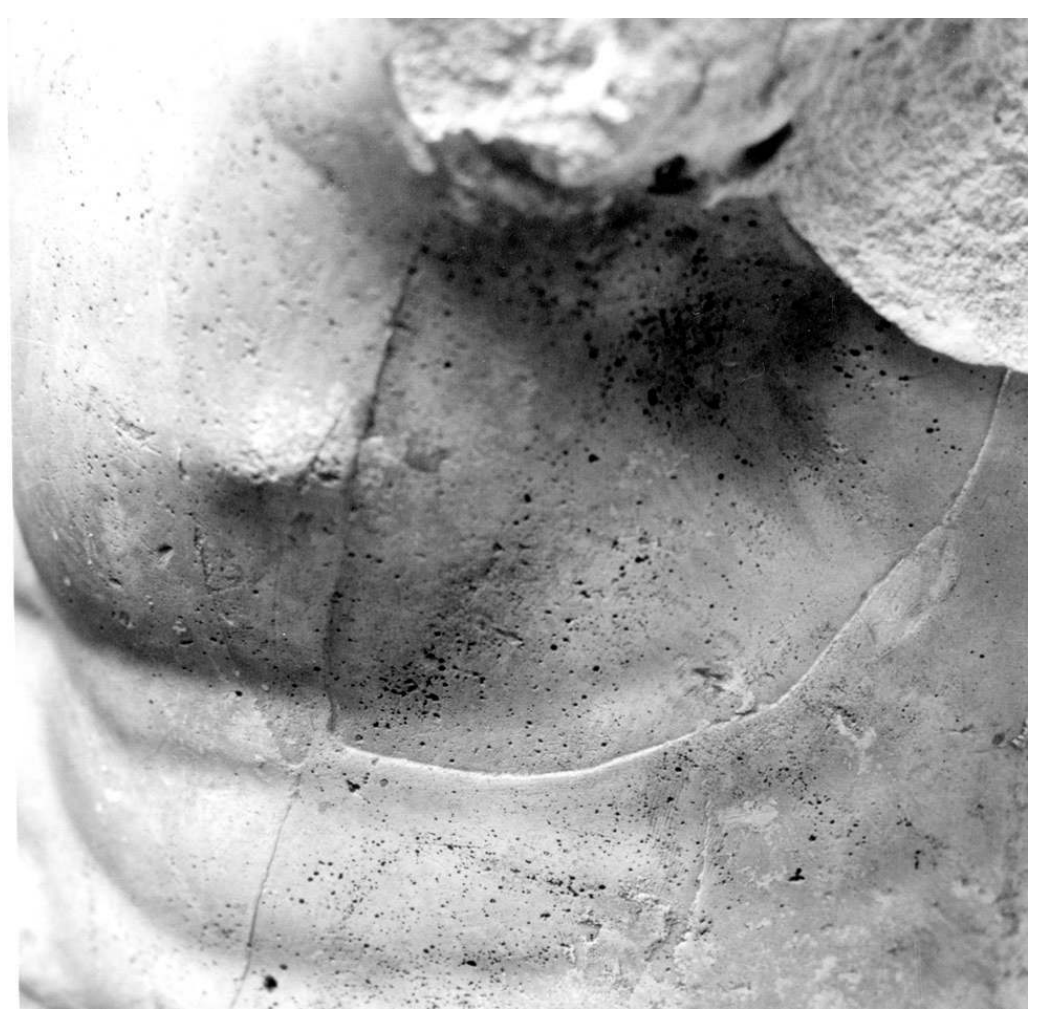

Le tirage du Gaulois mourant. Détail de coutures et d'un décalage de pièce. Phot. Roumégoux, P. @ Musée du Louvre.

\section{Figure 7}

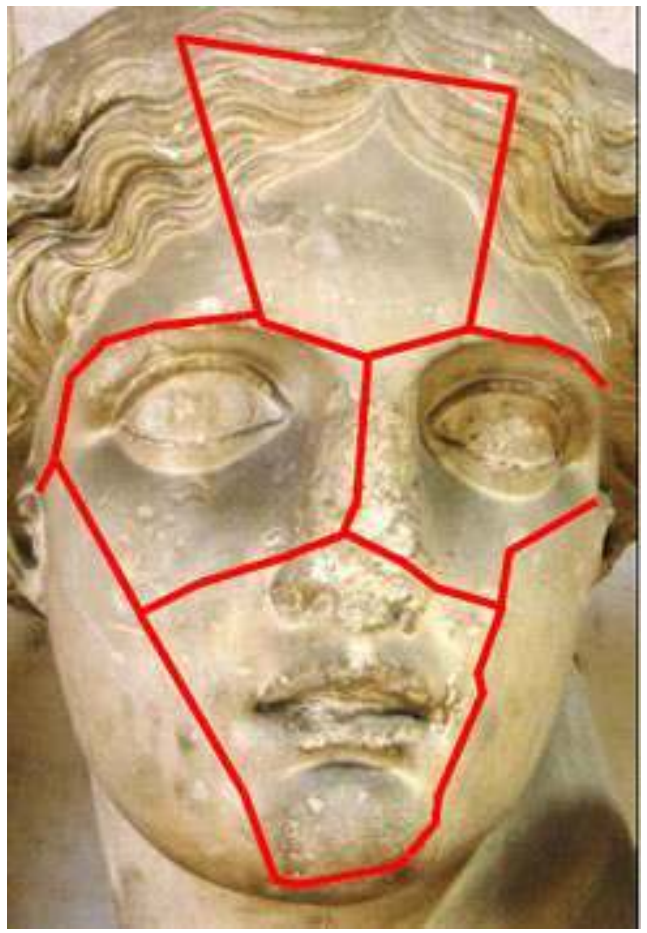

Tirage en plâtre d'une Tête colossale d'Artémis (?) provenant de Cherchel. ler siècle av. J.-C. Phot. Le Breton, É. @ Musée du Louvre. 
13 Le tirage proprement dit est plein, dense, avec une masse importante de $436 \mathrm{~kg}$. Il est réalisé, pour le corps, en plâtre gâché clair ${ }^{7}$, avec de ce fait, une certaine porosité et des bulles d'air en grand nombre. La terrasse semble avoir été tirée creuse, avant d'être armée d'éléments en bois ou en fer forgé, de section carrée, et comblée d'un plâtre gâché plus serré, mais aussi plus granuleux et friable. Ces armatures de fer forgé ne se retrouveront que dans les tirages fort anciens.

Au cœur de ces matériaux de constitution, révélant une qualité de broyage assez grossière et une cuisson partielle, il n'est pas rare de distinguer des inclusions de morceaux de gypse avec des cristaux incuits, d'aspect vitreux et jaunâtre, mais encore des traces de cendre, de charbon ou de résidus divers (fig. 8).

Figure 8

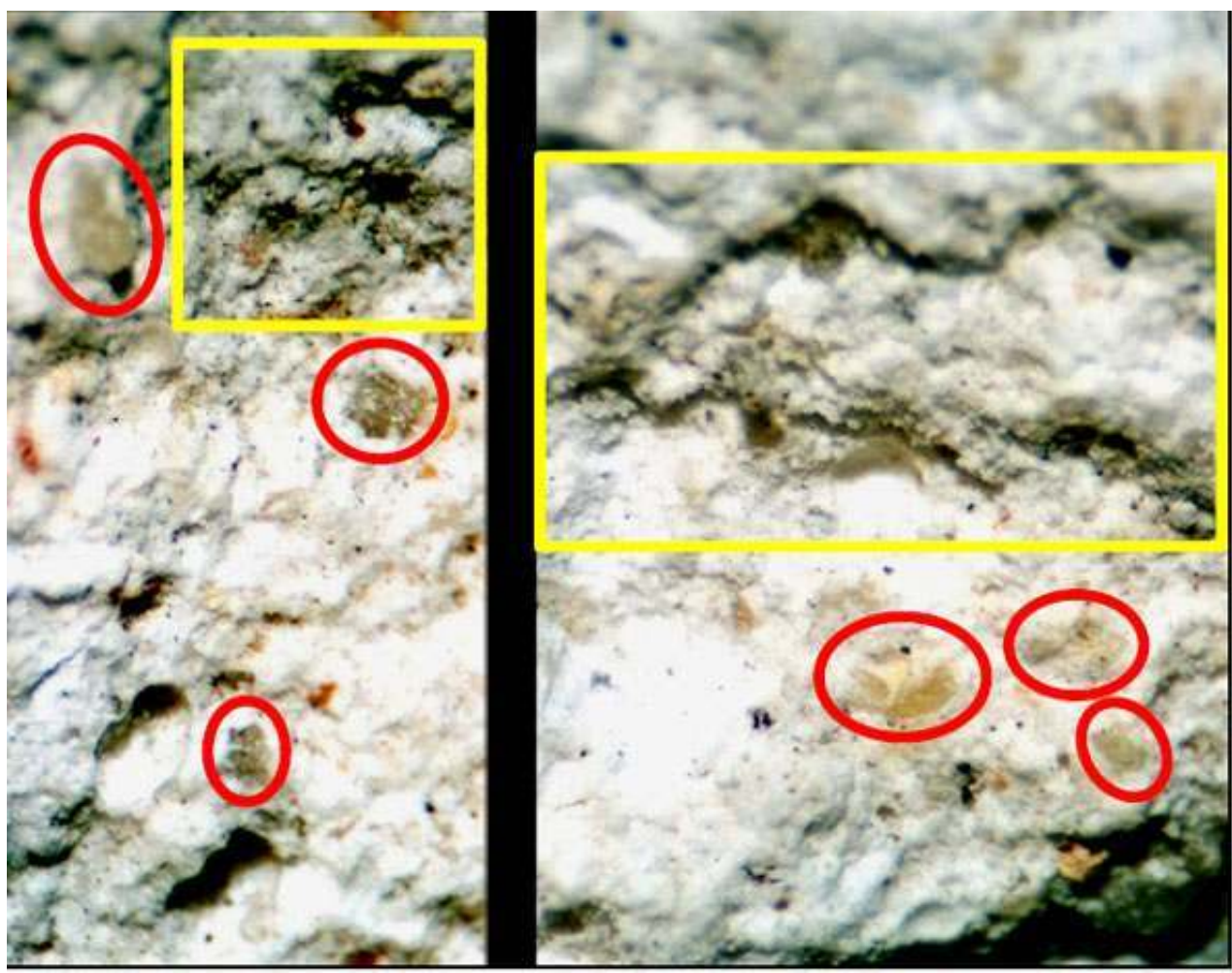

Le tirage du Gaulois mourant. Détail des plâtres de constitution sous loupe binoculaire avec, dans le plâtre de coulée, à gauche, des morceaux de gypse non cuits et des traces de charbon et les mêmes éléments, à droite, dans le plâtre de comblement.

Phot. Roumégoux, P. (c) Musée du Louvre.

15 La qualité du matériau, très dense, avec des impuretés, et la manière dont il est gâché, clair à très clair, sont expliquées par le mode de cuisson. Avant l'ère industrielle, le gypse est souvent mal cuit, dans des fours modestes et au bois. Il reste alors chargé de morceaux incuits et d'autres débris liés au matériau de chauffe, qui entraînent une augmentation de la densité générale et imposent ensuite un gâchage clair du fait de ces fragments à l'intérieur. Il peut être aussi plus souvent grisâtre.

À partir du XIX ${ }^{\mathrm{e}}$ siècle, les modes de cuisson sont grandement améliorés ; il en résulte une qualité de grains très fins, d'un blanc plus pur, permettant de gâcher serré. Les tirages sont alors plus systématiquement réalisés avec des moules à pièces en plâtre; tirés ensuite le plus souvent creux, ils sont de ce fait beaucoup plus légers. 
17 L'ensemble des éléments que nous venons d'examiner et de détailler avec le Gaulois mourant, nous aide à identifier clairement ce que nous considérons comme la carte d'identité de tirages caractéristiques d'une époque ancienne. Mais à ce stade d'observation, il reste prématuré de l'attribuer précisément au XVII ${ }^{\mathrm{e}}$ ou au XVIII ${ }^{\mathrm{e}}$ siècle. Il nous fallait trouver d'autres voies de réflexion. Le très mauvais état général de l'œuvre, associé à des marques inaccoutumées que le nettoyage de surface a clairement mises en évidence, nous a ouvert de nouvelles pistes de réflexion.

Figure 9

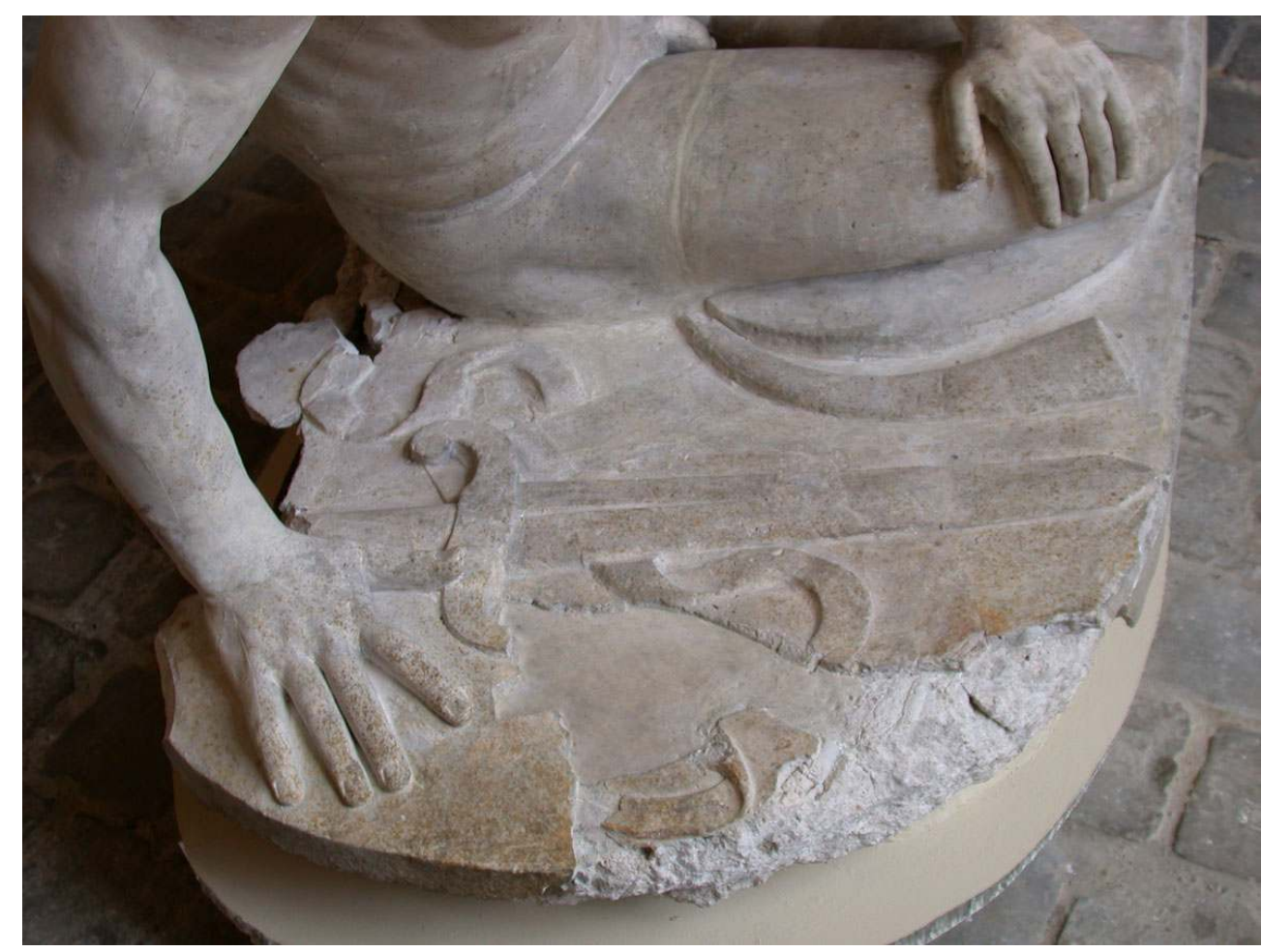

Le tirage du Gaulois mourant. Détail de la terrasse portant des traces de matériau type savon noir. Phot. Roumégoux, P. (C) Musée du Louvre.

18 On observe en effet, localisées sur une partie de la terrasse, des taches jaunes ocrées et satinées, inhabituelles. Elles ont pu être assimilées à des résidus d'un produit de type savon noir (fig. 9). Utilisé en général comme matériau de séparation, cette présence aida à concevoir l'idée que ce tirage ait pu faire l'objet d'une prise d'empreinte. Des traces d'outils en creux, clairement repérées, en particulier le long d'une couture au niveau de la clavicule gauche, ont confirmé que l'œuvre a bien été surmoulée (fig. 10). 
Figure 10

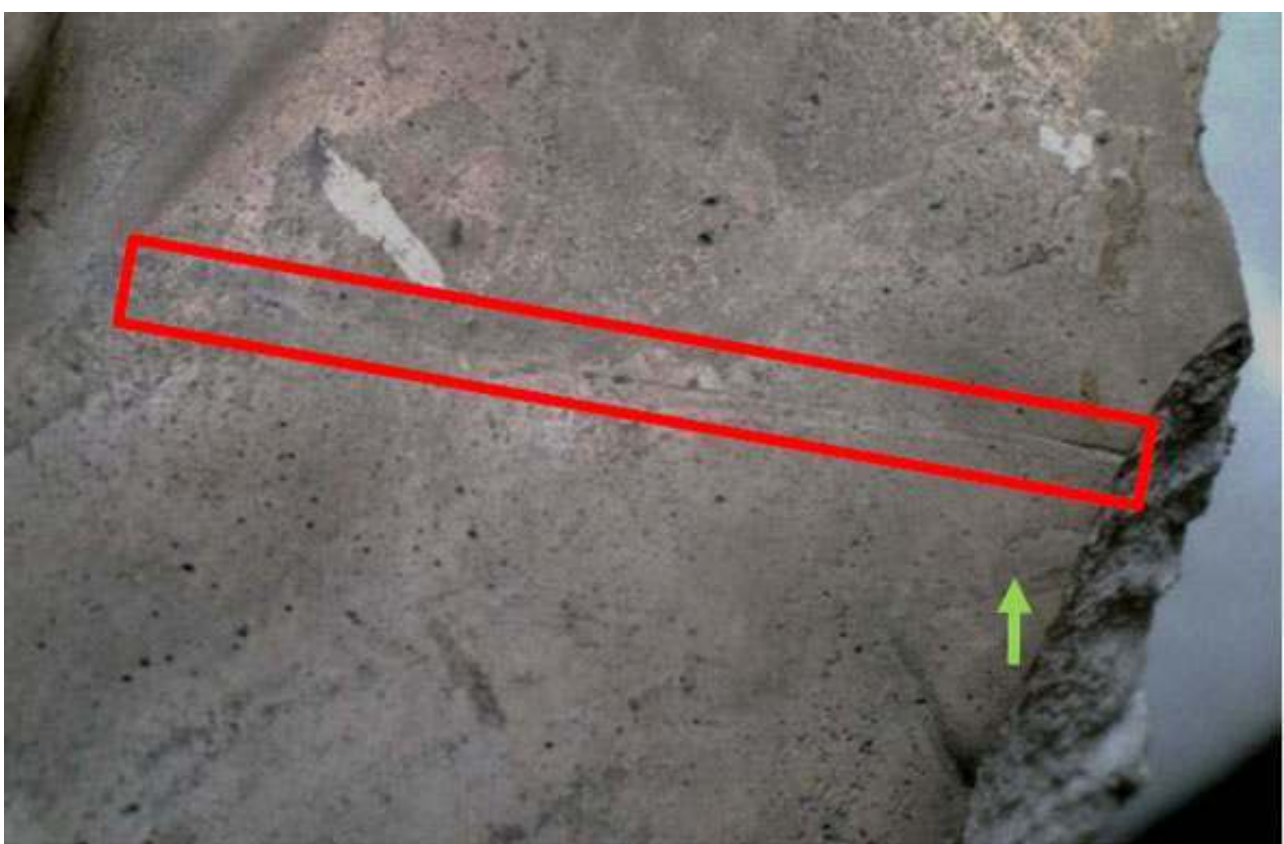

Le tirage du Gaulois mourant. Détails d'une couture et d'une incision le long de cette couture au niveau de la clavicule gauche.

Phot. Roumégoux, P. (c) Musée du Louvre.

19 Mais des séquelles d'interventions plus violentes sont venues étayer définitivement cette hypothèse. Si beaucoup d'œuvres arrivées dans la gypsothèque ont été victimes de découpages assez radicaux pour les déménagements dans les années 1970, le format du Gaulois mourant, en longueur, ne justifiait pas une mise en pièces telle qu'elle apparaissait encore. À un moment donné de son histoire, sans aucun lien avec les mesures agressives des transferts, l'œuvre a été démembrée (fig. 11); le buste désolidarisé de la terrasse, la tête, les deux bras et les deux jambes sectionnés nettement, avant que l'ensemble soit remonté. C'est simplement ce remontage, assez grossier et toujours perceptible, qui a lâché à l'occasion de différents déplacements. 
Figure 11

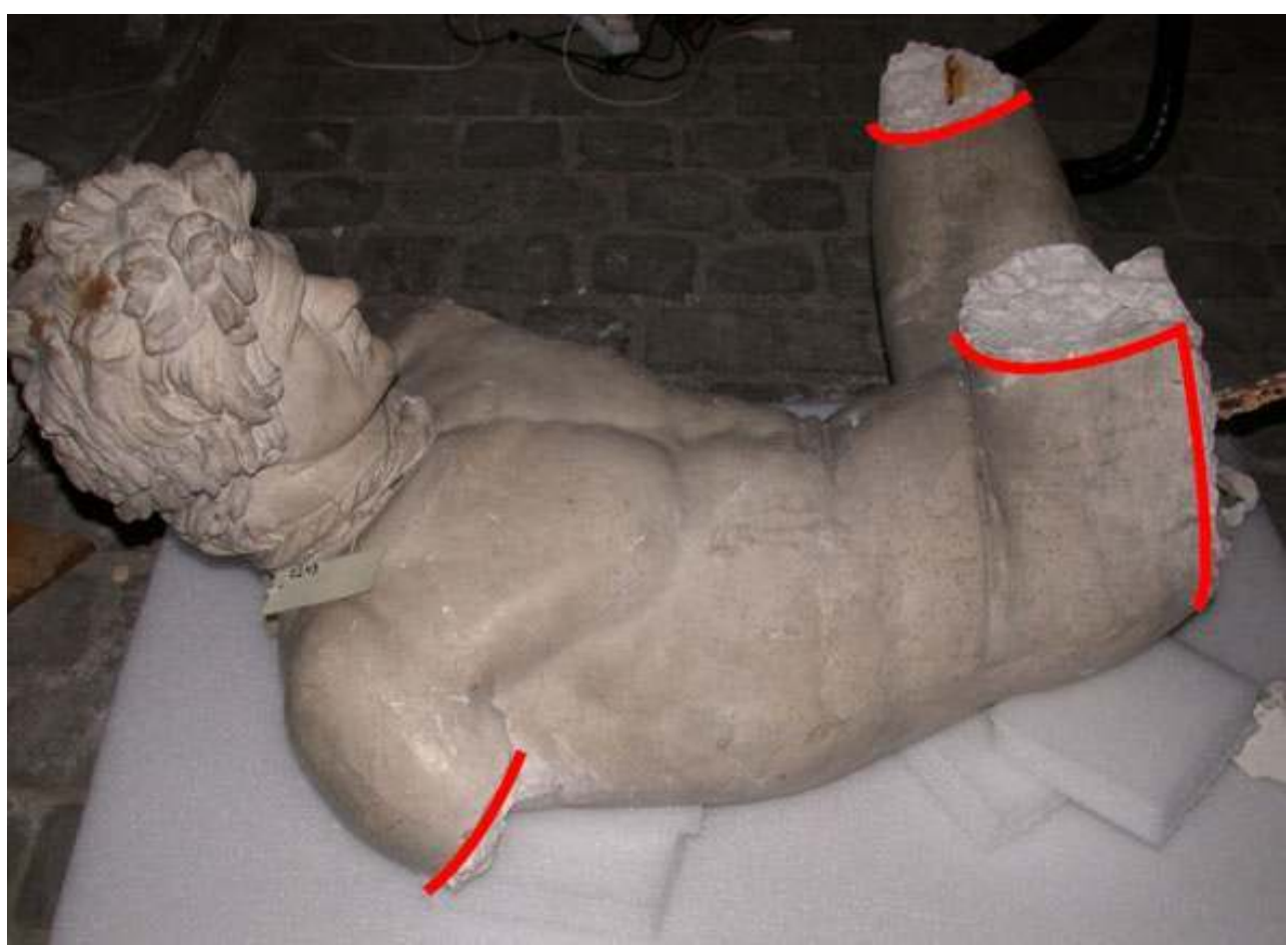

Le tirage du Gaulois mourant. Buste désolidarisé de la terrasse au moment de la restauration sur les bases des coupures nettes d'un sectionnement à la scie.

Phot. Roumégoux, P. (c) Musée du Louvre.

Ainsi, si nous ne sommes toujours pas en mesure de le dater, ni de dire à quelle collection appartenait ce tirage, une partie de son histoire s'éclaire; il a servi de modèle pour une autre réalisation. Mais laquelle? Et quel type d'œuvre peut exiger un découpage en pièces séparées?

21 Évidemment, ce ne peut être pour la réalisation d'une copie en marbre qui ne justifie aucune intervention invasive; les tirages en plâtre de Gaulois mourant des collections françaises n'avaient d'ailleurs aucunement servi de modèle au Gaulois mourant de Michel Monier ${ }^{8}$ qui orne les jardins du château de Versailles. Il a été réalisé lors du séjour de Monier comme pensionnaire à l'Académie de France à Rome, et a rejoint Paris en 1682. L'Académie possédait déjà une collection de modèles des grandes références antiques, mise à la disposition des artistes pensionnaires, qui exécutaient donc leurs travaux sur place.

La mise en pièces du tirage en plâtre ne se justifiait que pour une prise d'empreinte avant l'exécution d'un autre tirage ; restait alors à clarifier si c'était pour un tirage en plâtre ou en bronze.

Les abattis que nous venons d'évoquer ont en effet été moulés (incisions, présence des taches jaunes ocrées), puis réassemblés, jointoyés au plâtre (traces du remontage des différentes parties encore visibles, en particulier très nettement sous les fesses). C'est à la restauratrice Pascale Roumégoux que l'on doit d'avoir mis en évidence les correspondances de coutures assez singulières, avec celles qui figurent, parfois très discrètement du fait d'une abrasion, sur la fonte de 1688 du Gaulois mourant, en bronze, des collections du château de Fontainebleau. Il est possible de les repérer le long du torse, 
de l'aisselle à la fesse (fig. 12, fig. 13), à l'intérieur de la cuisse gauche ou encore le long de la clavicule droite (fig. 14), en regard avec l'incision repérée sur le tirage en plâtre.

\section{Figure 12}

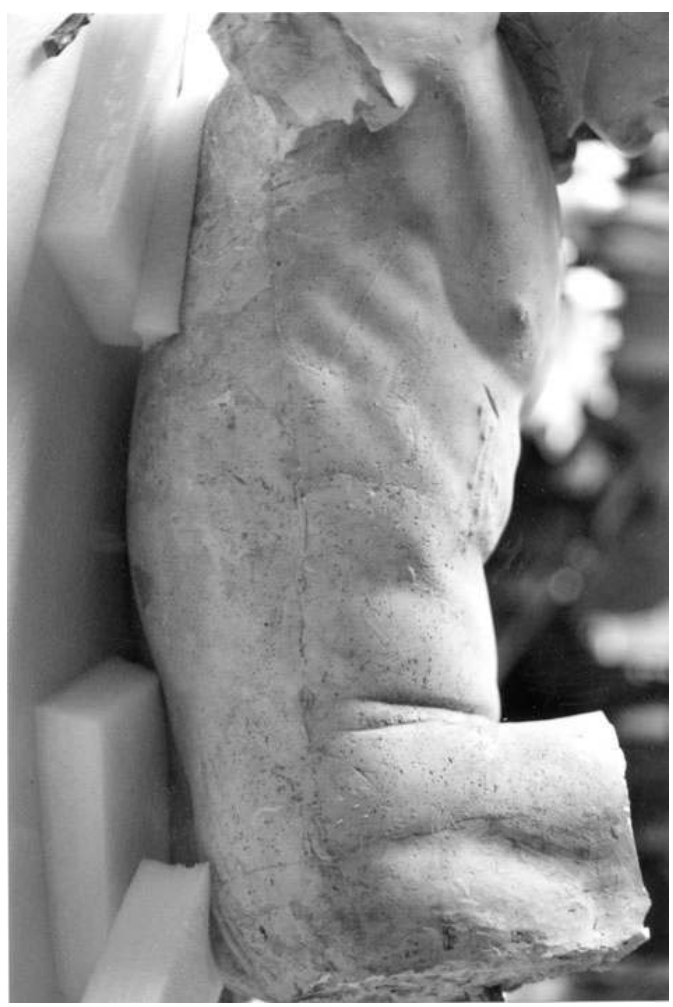

Le tirage du Gaulois mourant. Torse désolidarisé de la terrasse avec la couture latérale courant de l'aisselle jusqu'au bas de la fesse sur le côté droit.

Phot. Roumégoux, P. ( ) Musée du Louvre. 


\section{Figure 13}

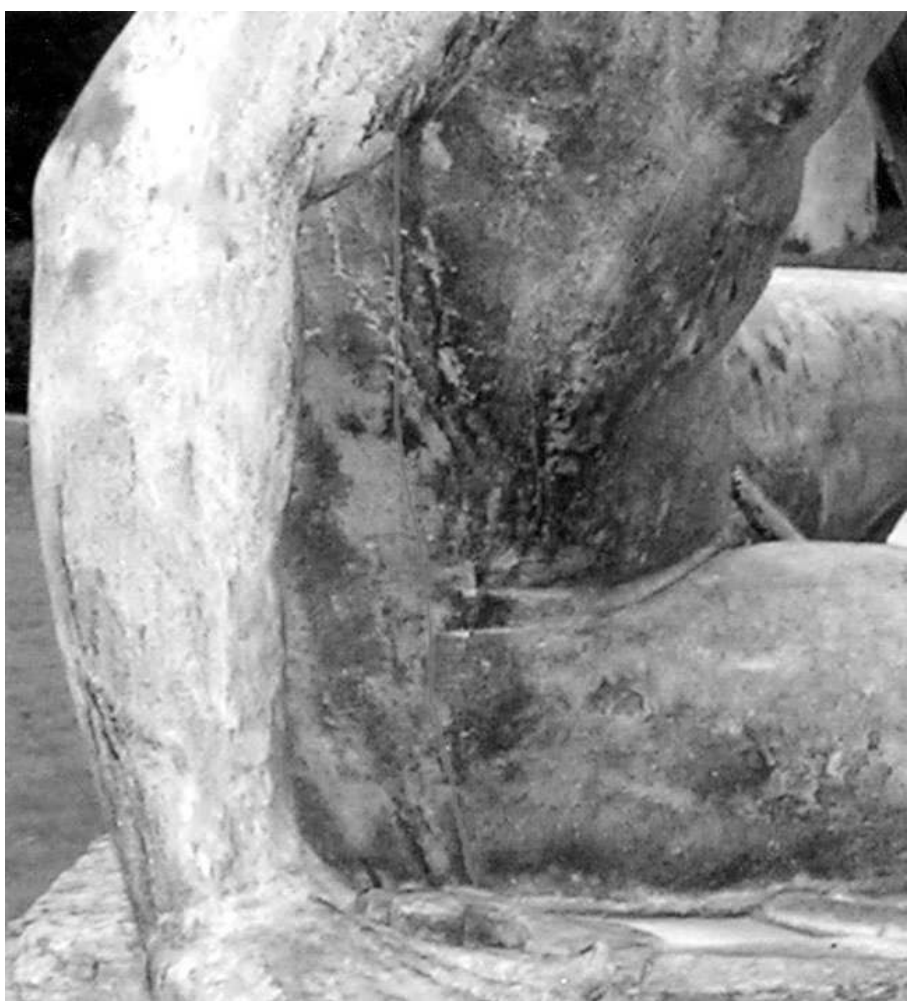

Le tirage du Gaulois mourant de bronze du parc de Fontainebleau. Détail du torse avec la couture latérale courant de l'aisselle jusqu'au bas de la fesse sur le côté droit.

Phot. Roumégoux, P. (c) Musée du Louvre. 
Figure 14

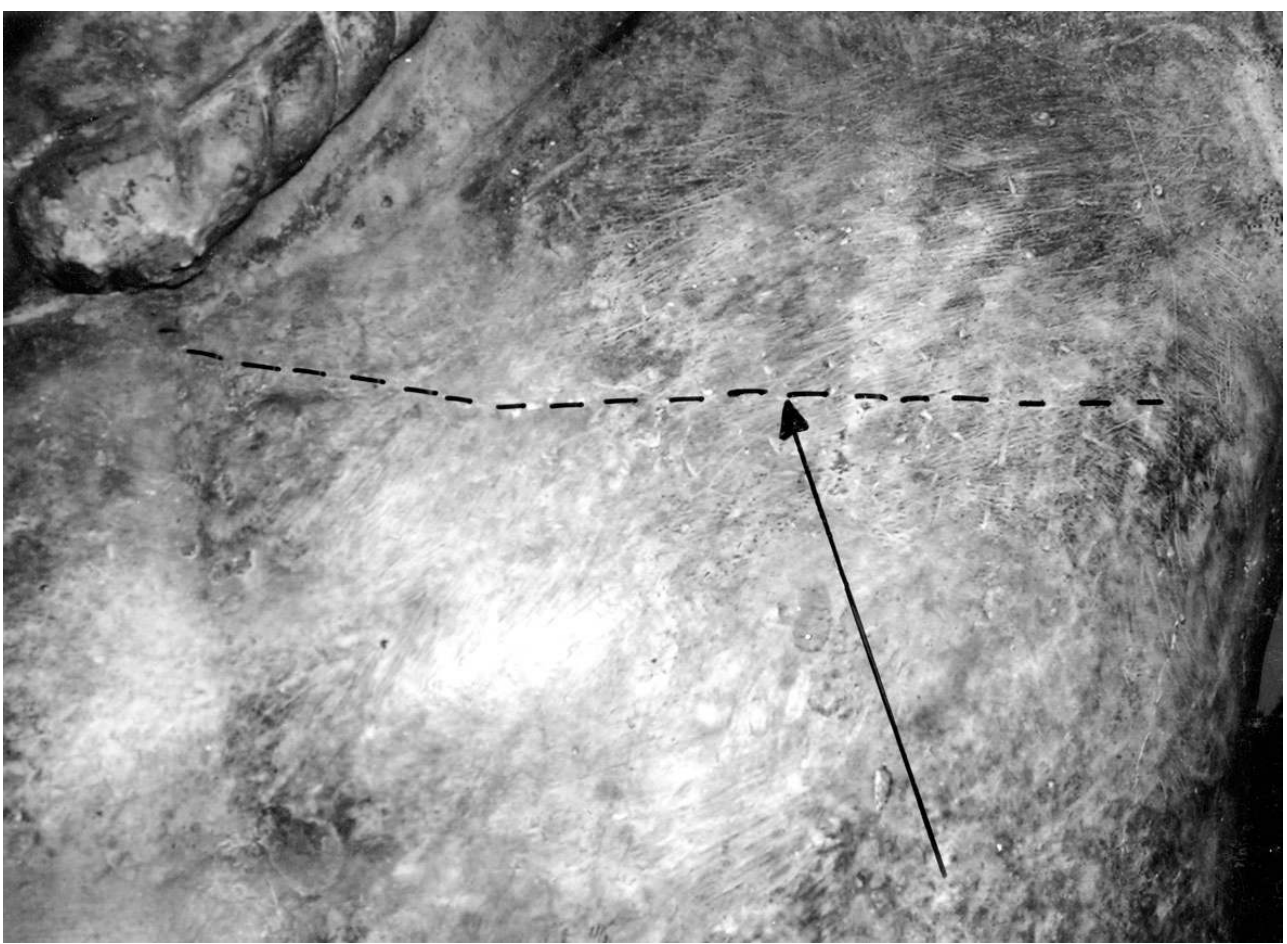

Le Gaulois mourant en bronze du parc de Fontainebleau. Détail du torse avec la couture au niveau de la clavicule.

Phot. Roumégoux, P. ㄷ Musée du Louvre.

En conclusion, ce dernier a bien servi de modèle au tirage en bronze déposé aujourd'hui dans le jardin anglais du château de Fontainebleau (fig. 15) et peut donc être daté, non pas du XVIII siècle, mais d'avant 1688. 
Figure 15

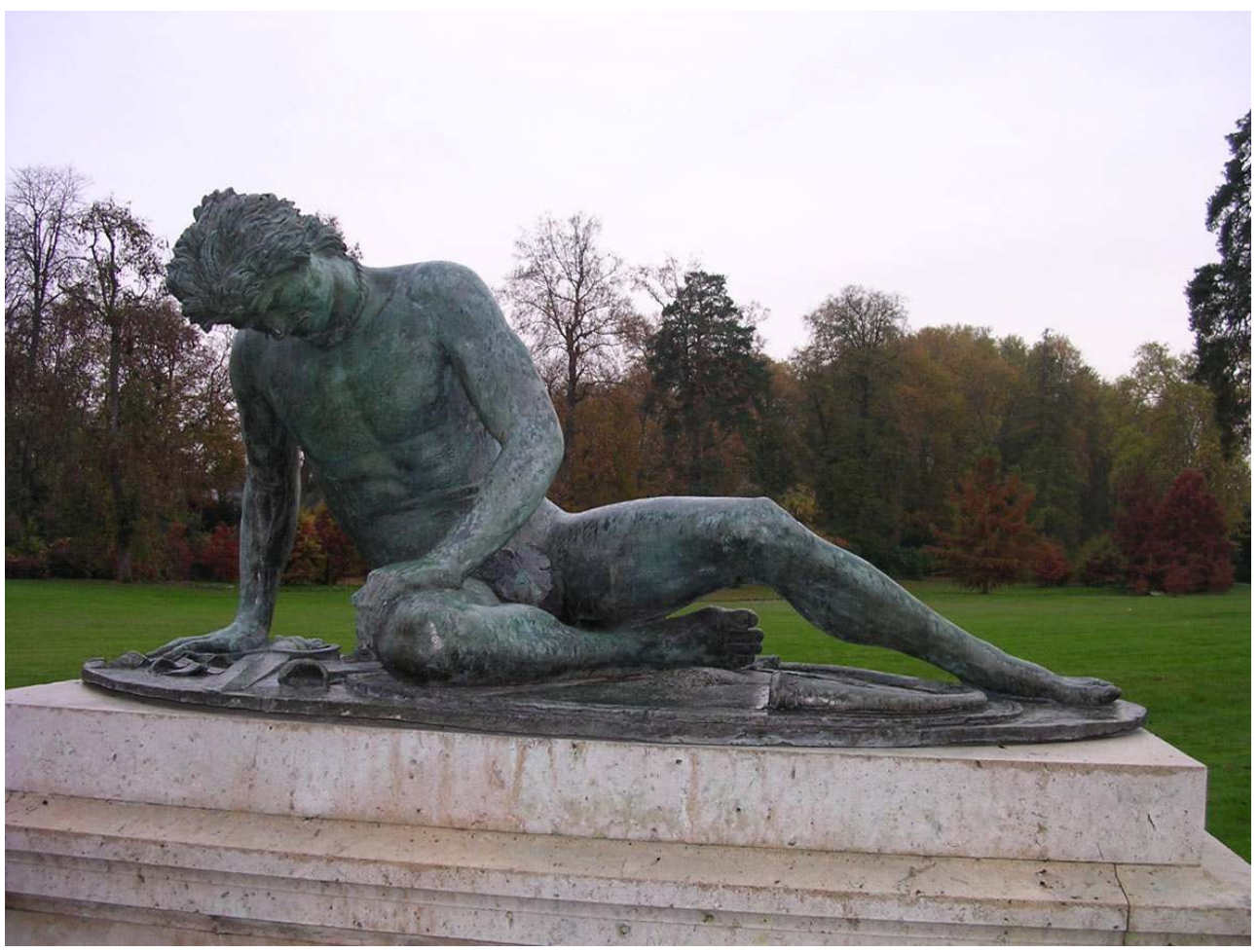

Le Gaulois mourant en bronze du parc de Fontainebleau.

Phot. Roumégoux, P. (c) Musée du Louvre.

25 Ainsi le Gaulois allait être celui grâce auquel nous obtiendrions la carte d'identité qui nous manquait pour dater indiscutablement des tirages du XVII ${ }^{e}$ siècle (fig. 16). 
Figure 16

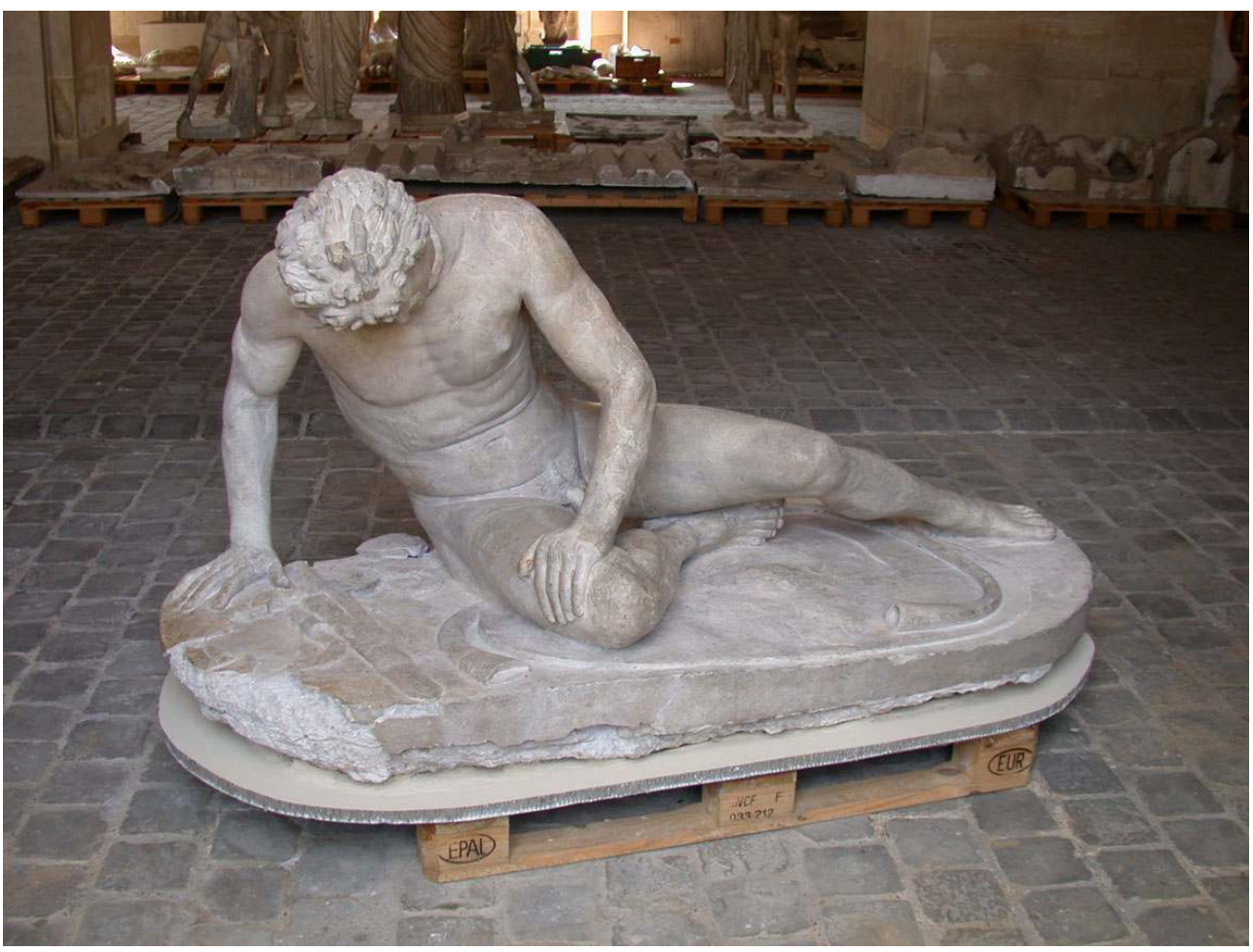

Le tirage du Gaulois mourant. État du tirage après sa restauration, déposé sur un nid d'abeille. Phot. Roumégoux, P. (c) Musée du Louvre.

\section{Un grand invalide redressé : l'Hercule Farnèse}

Le deuxième grand invalide de la gypsothèque a été restauré en 2006 et 2007. Il s'agit du tirage de l'Hercule Farnèse 9 (fig. 17, fig. 18). 


\section{Figure 17}

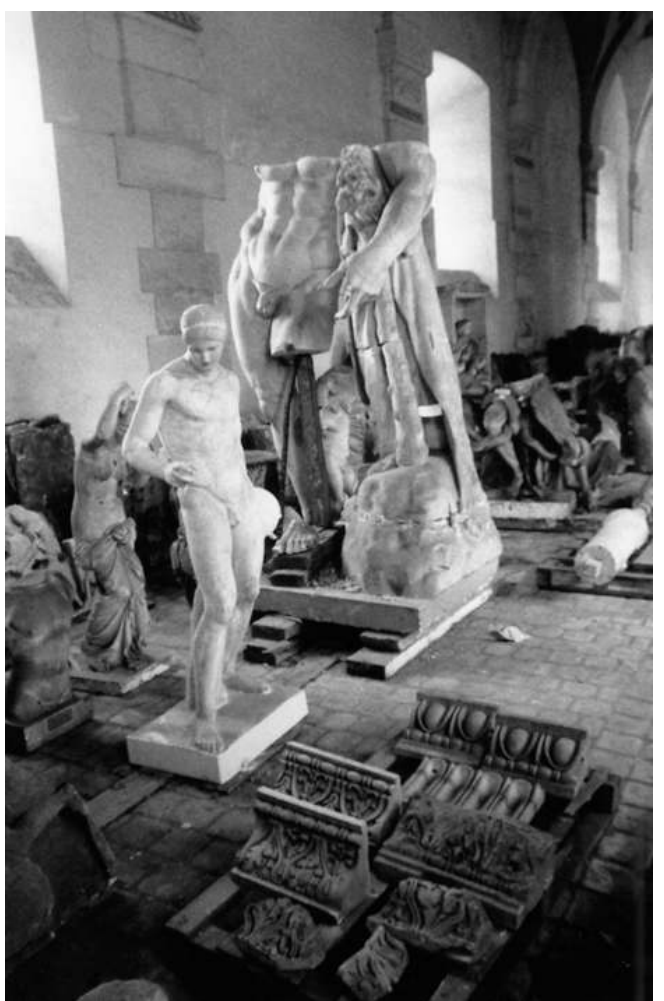

Le tirage de l'Hercule Farnèse. État à son arrivée dans la galerie nord/sud de la grande écurie du roi à Versailles, espace de réserve.

Phot. Pinatel, C. @ Musée du Louvre. 
Figure 18

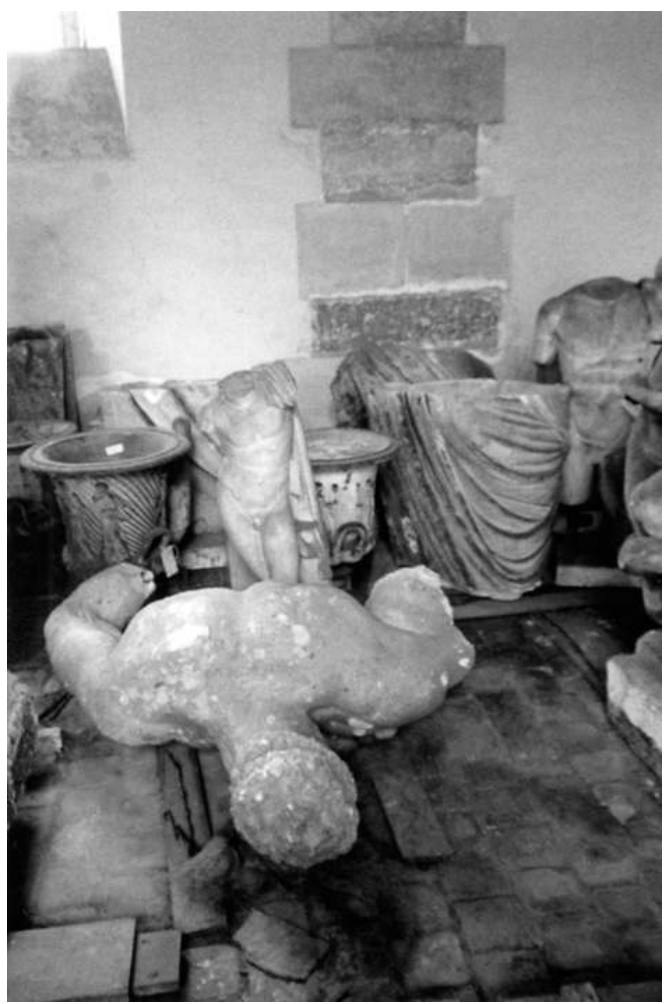

Le tirage de l'Hercule Farnèse. État à son arrivée dans la galerie nord/sud de la grande écurie du roi à Versailles, espace de réserve.

Phot. Pinatel, C. @ Musée du Louvre.

Toutes les données lisibles en surface de l'œuvre plaidaient d'emblée en faveur, au moins partiellement, d'une technique de moulage identique à celle observée pour le Gaulois mourant. C'est-à-dire une technique utilisant un moule à pièces en terre crue, appliqué par estampage.

La restauration a permis de repérer plus clairement encore ces empreintes de pièces et leurs décalages, et ce réseau de coutures si caractéristiques de cette technique; cela apparaît de manière très nette sur la tête notamment. Des restes d'inclusions d'argile retrouvés dans une cavité sont venus d'autre part confirmer l'usage de la terre (fig. 19). Néanmoins, il semble hasardeux de conclure que l'ensemble ait été réalisé selon cette méthode, car sur quelques zones, le corps en particulier, de nombreuses traces d'outils peuvent être observées et sont accompagnées d'un réseau de coutures si réparé que toute lecture claire est brouillée. L'usage d'une technique mixte, utilisant la terre comme le plâtre, doit être envisagé. 
Figure 19

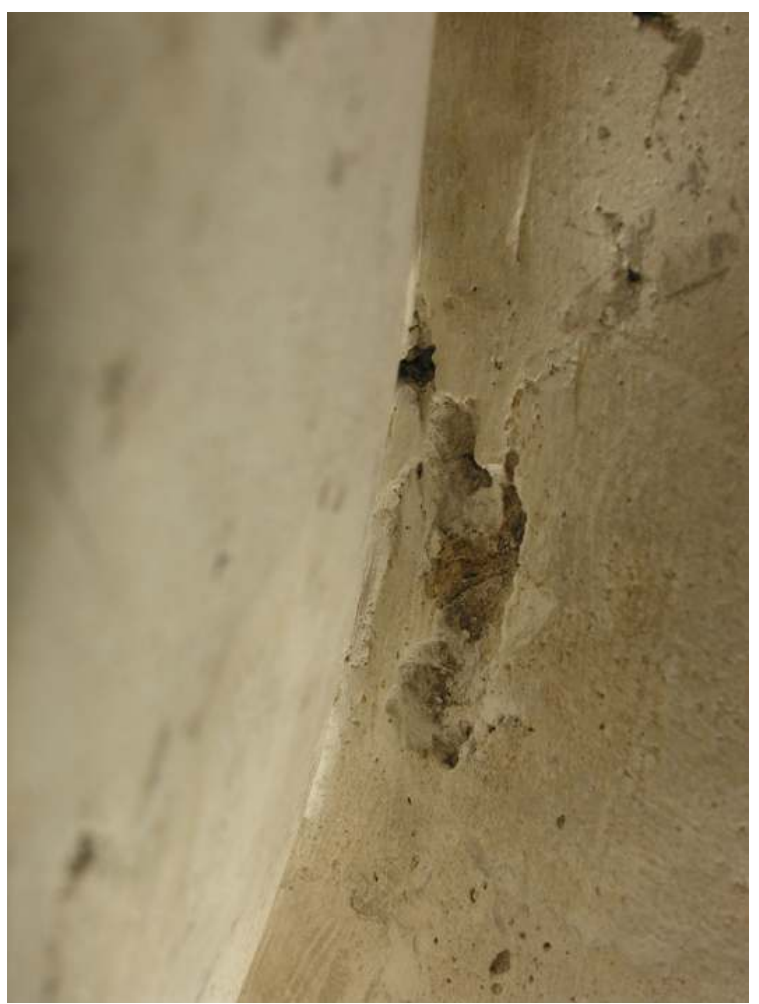

Le tirage de l'Hercule Farnèse. Détail d'une cavité avec des restes d'inclusion d'argile.

Phot. Roumégoux, P. ㄷ Musée du Louvre.

C'est à partir d'un examen de surface plus poussé qu'un autre indice important est apparu. Une fine couche uniforme d'argile recouvre toute l'œuvre, révélant que ce tirage aurait lui-même servi pour une prise d'empreinte (fig. 20); il aurait donc été surmoulé. Mais il présente encore une autre spécificité. Au niveau du visage, le réseau de coutures est clairement double à divers endroits, et associé à des incisions et autres traces d'outils (fig. 21). Autant d'éléments qui nous orientent donc vers un jet, qui serait en réalité non pas un tirage, mais un surtirage ${ }^{10}$, qui lui-même, aura été partiellement ou intégralement, moulé. En grande partie plein, c'est le cas pour les bras, les jambes et la tête, constitué d'un matériau assez fin et blanc, ce tirage est très dense avec une masse de $1200 \mathrm{~kg}$. Il est en plâtre gâché clair, avec de nombreuses bulles pour les plâtres de coulée et de comblement et beaucoup d'impuretés parmi lesquelles nous identifions de nouveau des morceaux de gypse incuits et des fragments de charbon dans les zones comblées. L'ensemble est armé d'éléments en fer forgé, de section carrée $(25 \mathrm{~mm}$ X $25 \mathrm{~mm})$ et de pièces en bois, localisées dans le corps d'Hercule ou dans le rocher; les pièces peuvent être placées en quinconce et renforcent efficacement l'ensemble. La base a été chargée de pierres, de briques et de bois. 


\section{Figure 20}

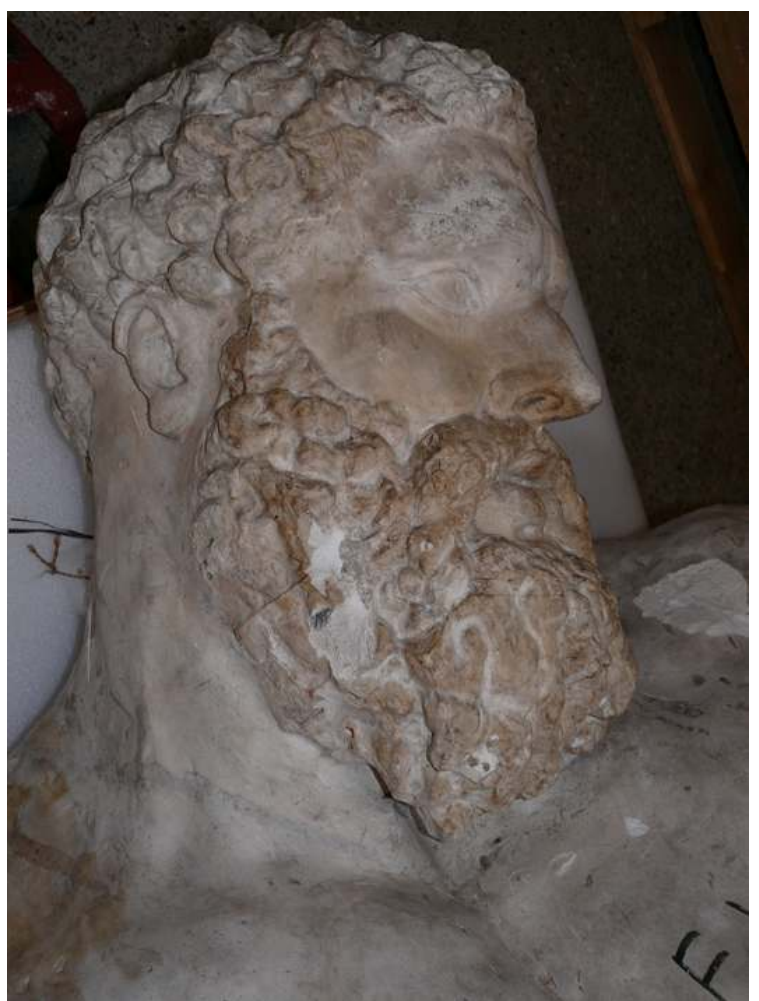

Le tirage de l'Hercule Farnèse. Détail de la tête, de profil droit avec la couche d'argile, le double réseau de coutures et les incisions.

Phot. Roumégoux, P. (c) Musée du Louvre. 
Figure 21

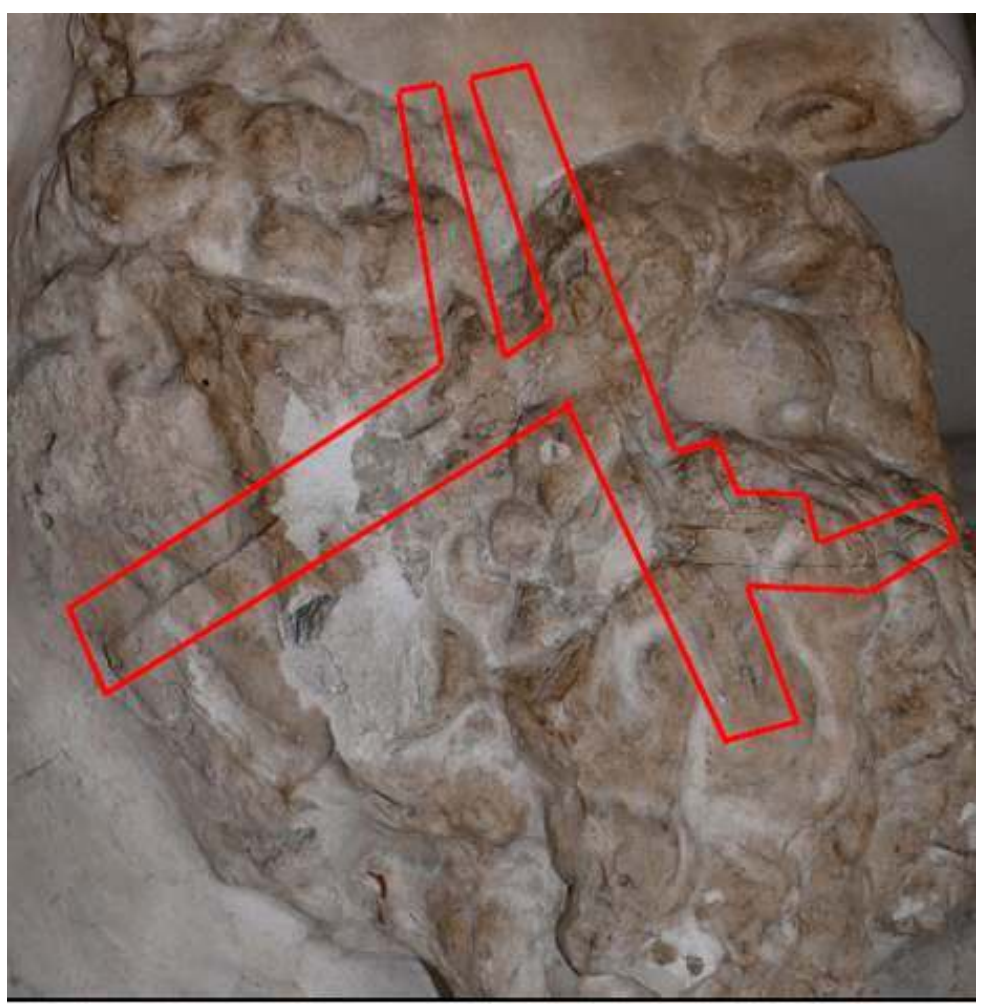

Le tirage de l'Hercule Farnèse. Détail de la tête avec, dans le champ, le double réseau de coutures et les incisions.

Phot. Roumégoux, P. ㄷ Musée du Louvre.

En surface, sur l'ensemble de l'œuvre, ont été repérées un grand nombre de croix de mise au point (fig. 22). 


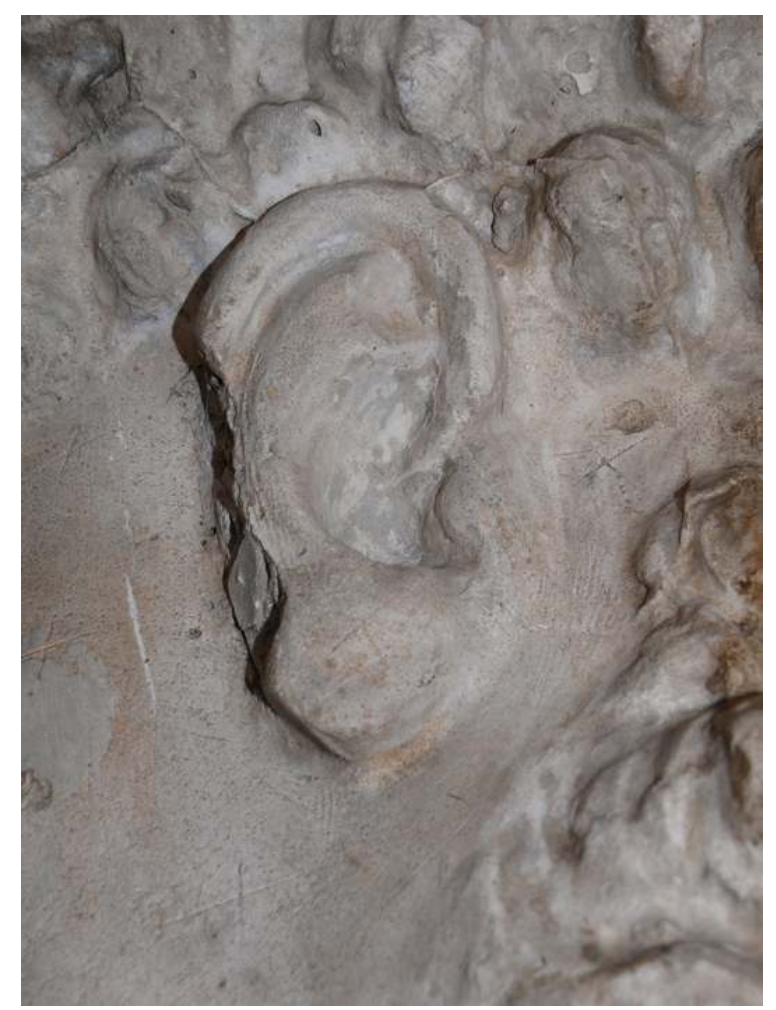

Le tirage de l'Hercule Farnèse. Détail du visage au niveau de l'oreille droite avec, dans le champ, les croix de mises au point incisées.

Phot. Roumégoux, P. (C) Musée du Louvre.

$31 \mathrm{Au} \mathrm{XVII}{ }^{\mathrm{e}}$ siècle, deux Hercule figurent au Louvre ${ }^{11}$, l'un dans la salle des Antiques ${ }^{12}$, et l'autre, commandé par Colbert, obtenu par surmoulage, et offert par le roi à l'Académie royale ${ }^{13}$.

La restauration a permis d'identifier avec certitude tous les éléments constituant la carte d'identité d'un tirage très ancien, mais aussi parfait, qu'il s'agit d'un surtirage. Des analyses de matériau effectuées par ailleurs ont conclu à l'usage d'un plâtre du Bassin parisien. Il est ainsi tentant de reconnaitre le fruit de la commande passée par Colbert, réalisé à partir de l'Hercule du sieur Thibault Poissant jeté à Rome en 1646 (antérieur à la création de l'Académie de France à Rome), modifié pour les jambes, à Paris et restauré en 1666 sous l'œil vigilant de l'Académie avant d'être moulé et tiré vraisemblablement en $1667^{14}$. L'Hercule Colbert est donc immanquablement un surtirage.

Les nombreuses traces de réparations observées sur l'œuvre peuvent s'expliquer, mais nous n'en avons aucune preuve, par une reprise suite à un accident survenu à l'occasion d'un déménagement depuis l'École royale des beaux-arts ; l'épisode est documenté ${ }^{15}$ et nous apprenons que «L'Hercule Farnese a été emporté, mutilé et mis en morceaux à cause des armatures en fer dont il étoit garni en dedans ».

Toutefois, s'il est tentant de reconnaître le « surtirage Colbert ", il reste, nous semble-t-il, bien difficile d'être formel. Sieur Thibault Poissant, qui exécute le surmoulage, demande à pouvoir retenir un creux avant de l'apporter à l'Académie. Rien ne nous permet de dire qu'il ait bien obtenu cette autorisation, ni qu'il ait (ou non) réalisé cette empreinte, puis un jet. 

doit son allure de grand blessé (fig. 23).

Figure 23

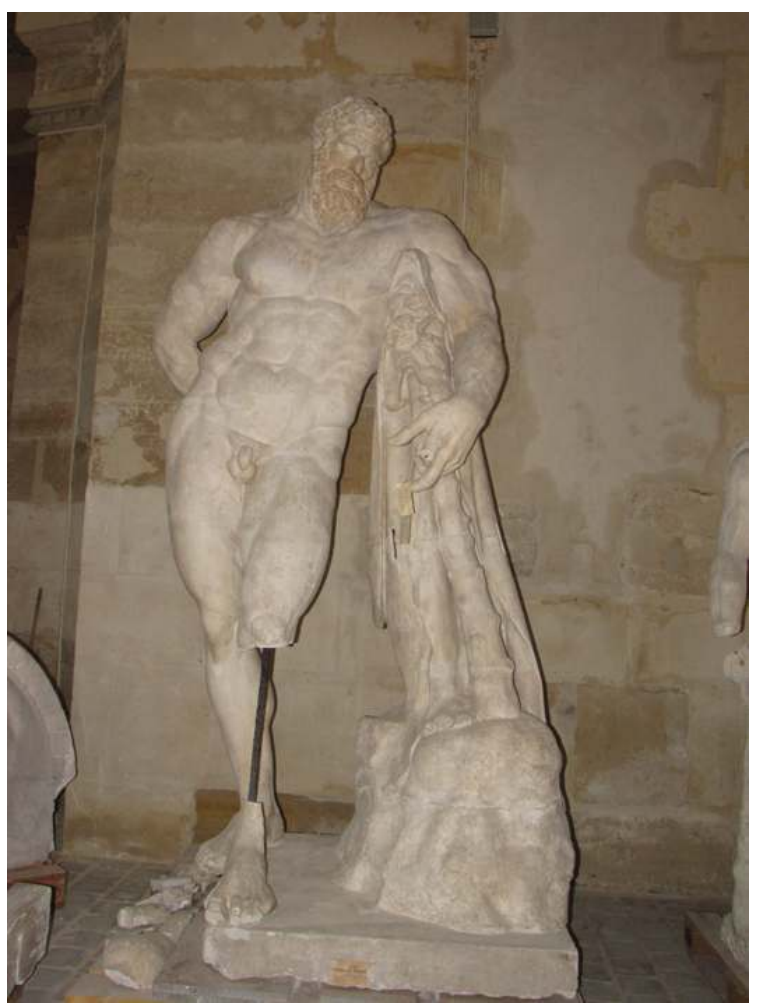

Le tirage de l'Hercule Farnèse après sa restauration.

Phot. Joudrier, A. (c) Musée du Louvre.

\section{Un cas très singulier : Commode en Hercule}

C'est aussi en 2007 que fut restauré Hercule portant Télèphe ou Commode en Hercule ${ }^{16}$ (fig. 24). 
Figure 24

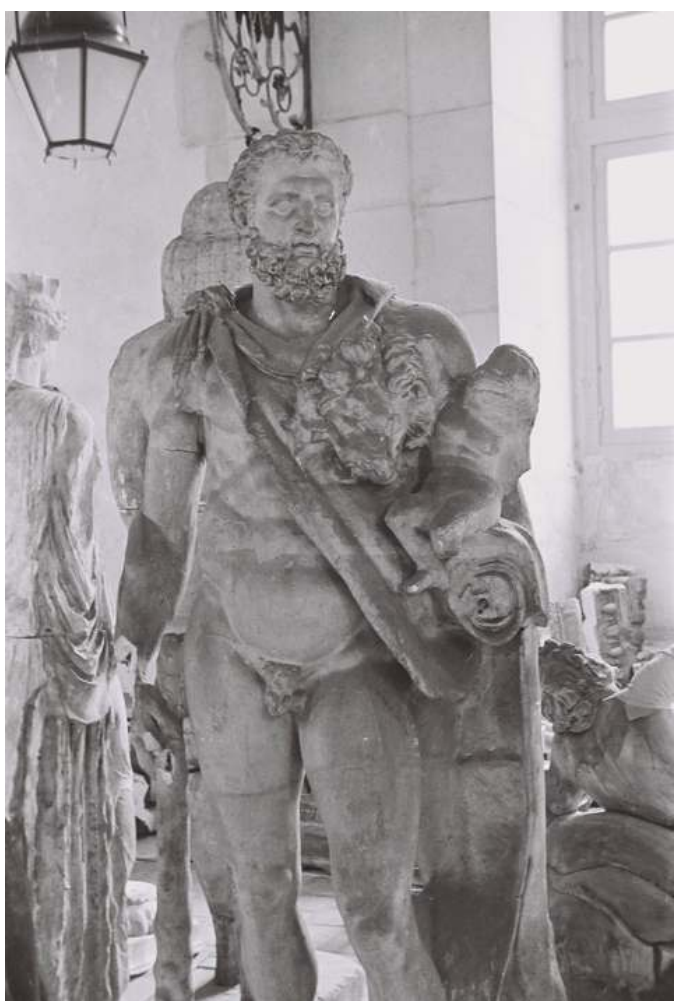

Le tirage de Commode en Hercule. État à son arrivée dans la galerie nord/sud de la grande écurie du roi à Versailles, espace de réserve.

Phot. Pinatel, C. @ Musée du Louvre.

Ce tirage, réalisé en plusieurs sections, à partir d'un plâtre d'assez belle qualité, avec peu d'impuretés, présente un aspect singulier par rapport aux deux autres tirages que l'on vient d'observer en détail. Cela se manifeste dans l'ensemble des caractéristiques lisibles en surface mais encore dans l'apparence du matériau ; tout semble ici en effet plus épais et marqué en même temps que de bien piètre définition. 


\section{Figure 25}

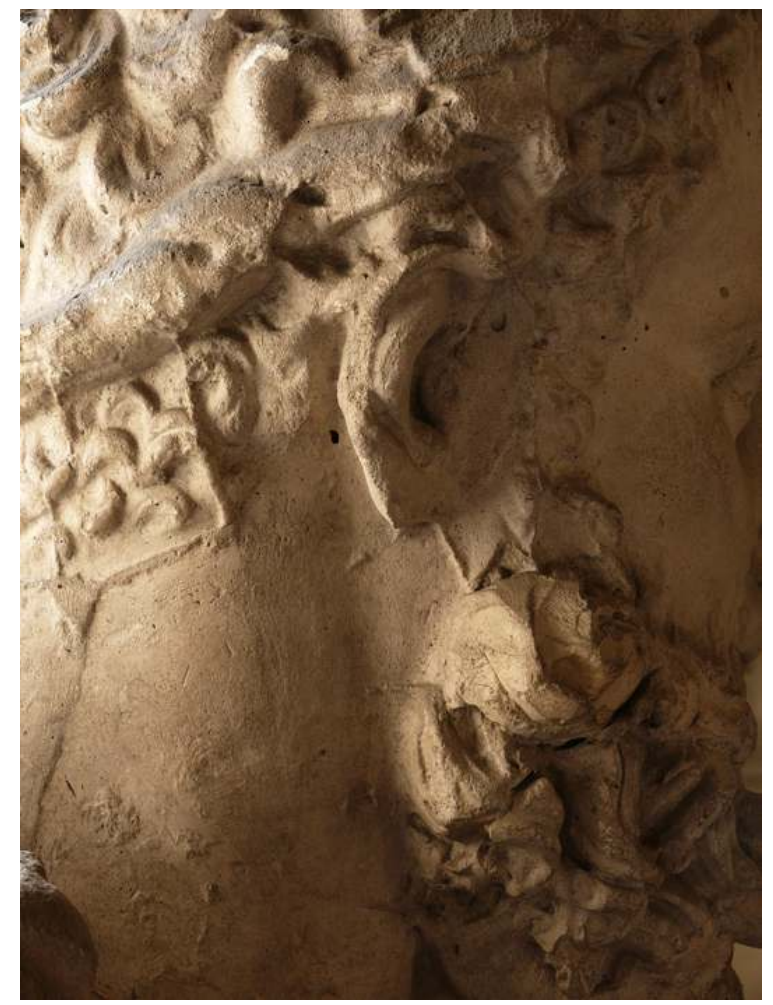

Le tirage de Commode en Hercule. Détail au niveau de la tête et de la nuque, à l'arrière, de coutures larges aux crêtes écrasées avec empreinte de pièces de petites dimensions, dont l'une d'elle sous l'oreille, avec un angle pointu.

Phot. Roumégoux, P. ㄷ Musée du Louvre. 


\section{Figure 26}

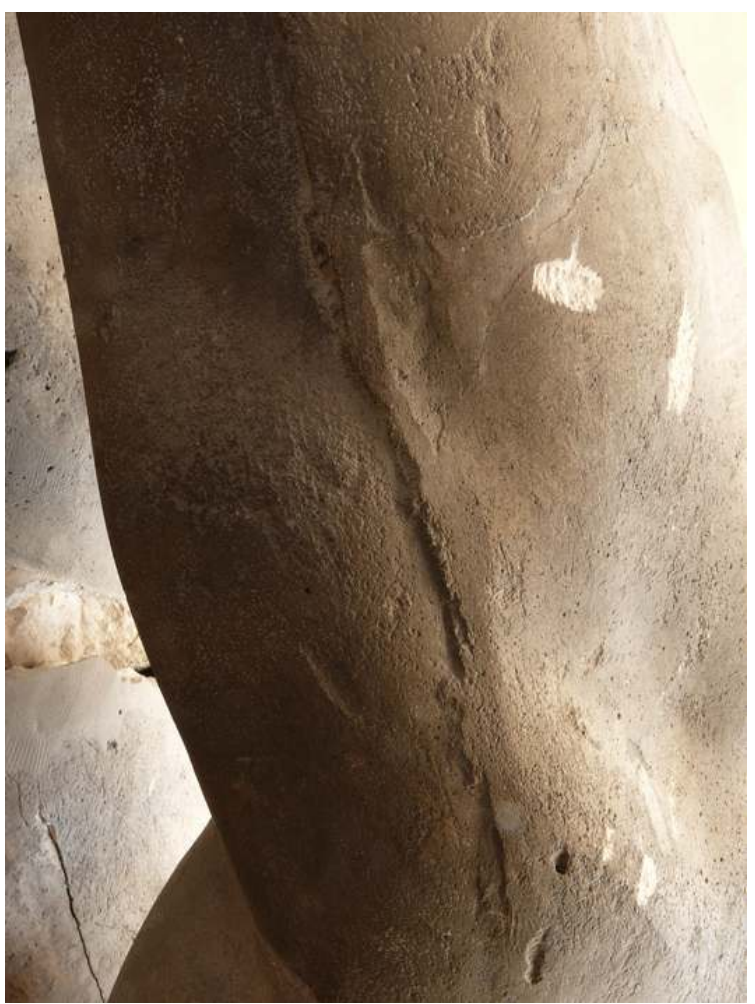

Le tirage de Commode en Hercule. Détail au niveau d'une jambe d'une couture épaisse avec une crête écrasée.

Phot. Roumégoux, P. ㄷ Musée du Louvre.

L'œuvre a clairement été jetée à partir d'un moule à pièces en terre et tous les éléments attendus pour le prétendre sont bien là. Il existe cependant des différences notables par rapport au Gaulois mourant ou à l'Hercule Farnèse; le réseau de coutures est vraiment beaucoup plus épais (fig. 25, fig. 26), et les marques de décalage de pièces étonnamment plus importantes (fig. 27). Ce tirage est plein, très dense, exécuté dans un matériau au grain perceptible, poreux, avec de nombreuses bulles apparentes. 
Figure 27

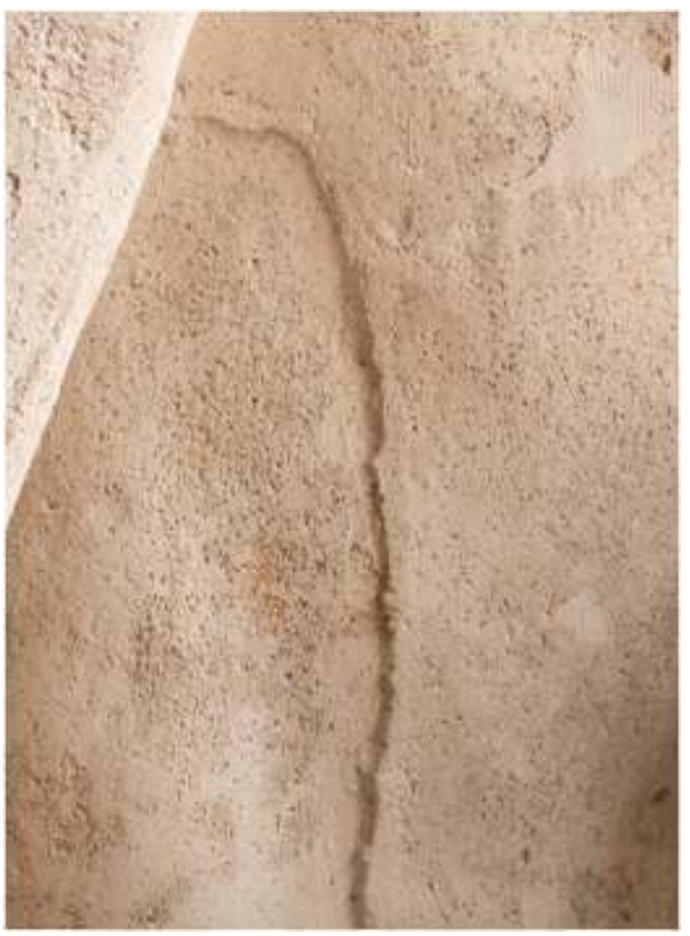

Le tirage de Commode en Hercule. Détail d'une couture avec un décalage de pièce. Phot. Roumégoux, P. @ Musée du Louvre.

41 L'ensemble est armé ou maintenu par des éléments en fer forgé, de section carrée (fig. 28). 


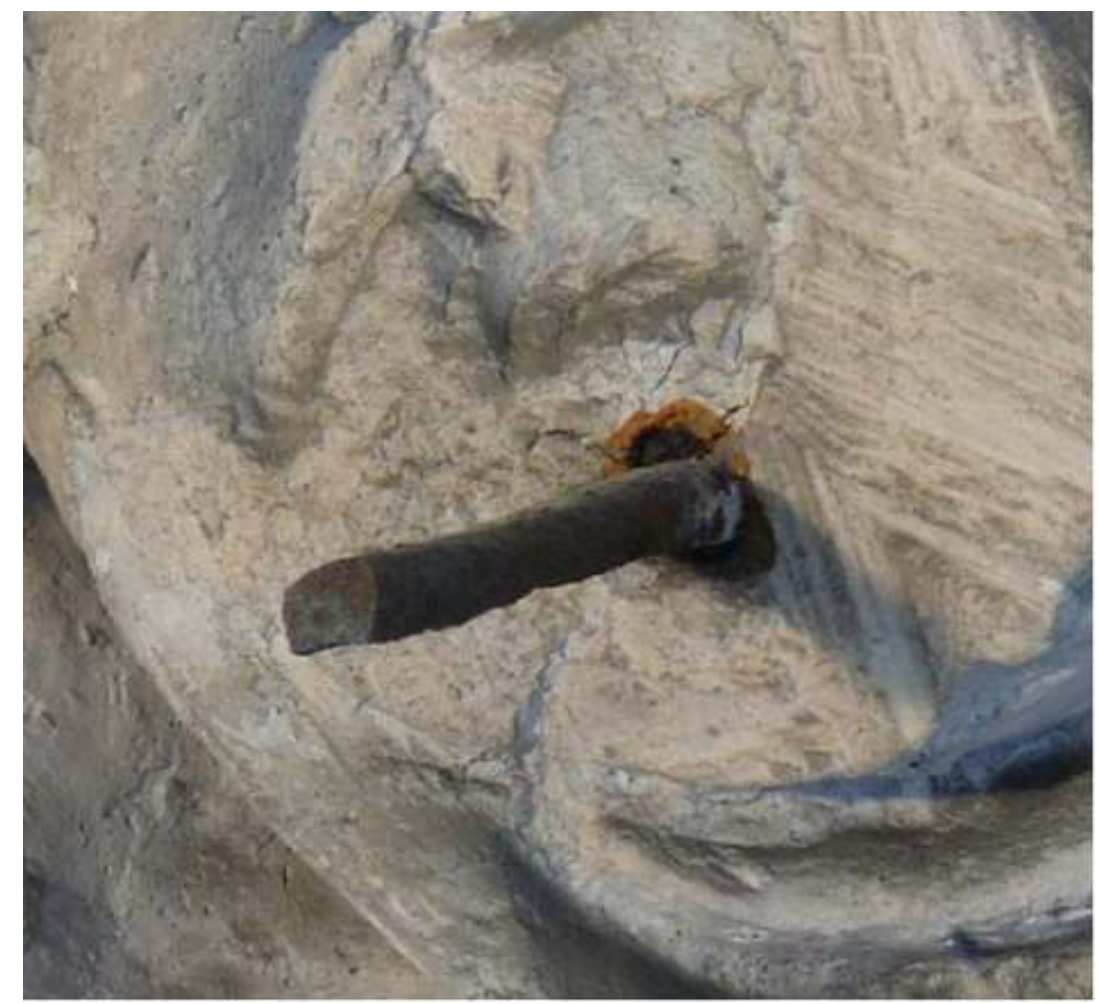

Le tirage de Commode en Hercule. Détail d'une armature en fer forgé.

Phot. Roumégoux, P. @ C Musée du Louvre.

Le matériau proprement dit présente assez peu d'impuretés sur les plans de cassures au niveau du corps de Commode, davantage sur les parties lacunaires du pourtour de la terrasse. Toutefois, ce tirage, beaucoup moins endommagé que les précédents, n'offre pas accès à autant d'informations.

L'enfant, solidaire de la section du torse jusque sous le mollet, c'est-à-dire non traité à part comme un abattis, est ici, comparé à l'original, une suggestion du Télèphe. S'il présente un état général, de surface et de matériau, qui paraît encore plus grossier et singulier qu'Hercule, il est surtout très éloigné de l'enfant porté par l'Hercule des collections du Vatican. La masse de plâtre, informe pour la tête, ébauchée pour le corps, à peine formée pour les membres supérieurs dont les avant-bras sont absents, laisse à penser que le tirage de l'enfant a connu un accident à un moment de son histoire et a été grossièrement repris, mais rien ne transparait d'un tel épisode, ou encore, que le modèle de l'enfant n'était pas spécialement recherché.

De ce groupe se dégage ainsi l'impression générale qu'il fut jeté avec des matériaux de second choix, dans un moule de médiocre qualité et/ou ayant beaucoup souffert, ce qui expliquerait la grande mollesse de définition des volumes, les traits gommés par rapport à l'original, et sans aucune finesse de détail.

Quelques traces, discrètes, pourraient être apparentées à des croix de mise au point. Cela reste très incertain.

Le modèle était déjà connu en France pour avoir été rapporté par le Primatice au XvI siècle, pour en réaliser une fonte pour Fontainebleau. A-t-on pu mouler un tirage en 
bronze ? Nous ne sommes pas en mesure de répondre à cette question pour le moment. Mais il convient clairement de s'interroger car cette œuvre est à classer à part dans le groupe des pièces que nous datons $\mathrm{du} \mathrm{XVII}^{\mathrm{e}}$ siècle; il est très éloigné de l'original. La tradition veut que les plâtres du XVI ${ }^{e}$ siècle aient tous disparu. Il conviendra peut-être de se pencher un peu plus sur ce sujet.

Quoi qu'il en soit, au XVII ${ }^{\mathrm{e}}$ siècle, un Hercule portant Télèphe est bien présent à la fois dans la salle des Antiques du roi ${ }^{17}$ et dans les salles de l'Académie ${ }^{18}$ au Louvre. Par la suite, on le reconnaît au moins à deux reprises comme modèle de référence dans les copies en marbre exécutées pour le Tapis vert et les rampes du parterre de Latone des jardins de Versailles suite à la commande de Louvois en 1683. La copie qu'en réalise en France Noël $\mathrm{V}$ Jouvenet en 1685 pour l'ornementation du Tapis vert est comparable au tirage de Versailles; le tirage de la gypsothèque fut-il précisément son modèle? Le marbre que réalise Nicolas Coustou a en revanche été exécuté à Rome, lors de son séjour comme pensionnaire à l'Académie de France; il se distingue du tirage de la gypsothèque néanmoins par l'absence de Télèphe, et Commode en Hercule est alors représenté portant les pommes du jardin des Hespérides. Il est installé sur la rampe entre 1683 et 1686 . Un modèle préliminaire, en terre cuite, a été exécuté, il est conservé dans les collections du musée du Louvre ${ }^{19}$.

Si nous ne pouvons assurer à quelle collection a pu appartenir le tirage du musée du Louvre (fig. 29), nous pensons être en présence de celui que l'on trouve dans la liste de $1817^{20}$, c'est-à-dire dans la liste qui fait état des objets déposés au collège des QuatreNations.

Figure 29

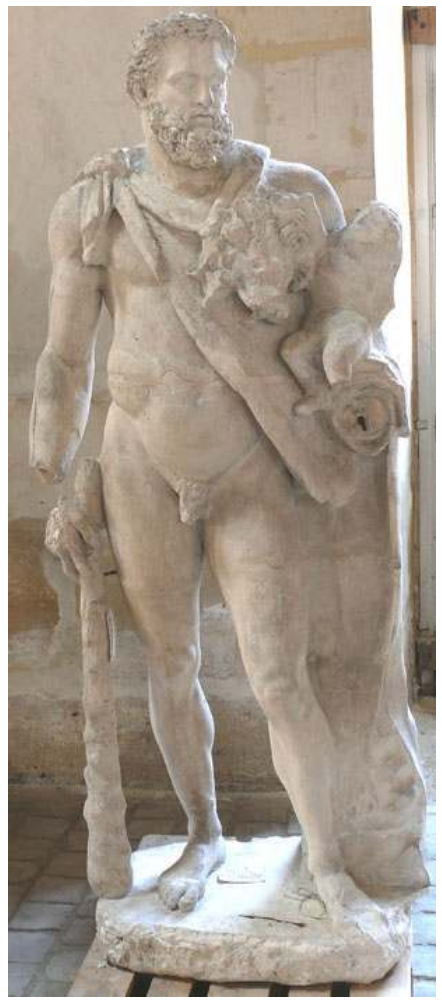

Le tirage de Commode en Hercule après sa restauration

Phot. Le Breton, É., 2012. @ Musée du Louvre. 


\section{Dans la salle des antiques du roi : Auguste et César}

Les statues colossales dites d'Auguste ${ }^{21}$ (fig. 30) et de César ${ }^{22}$ (fig. 31) dont les marbres sont au musée du Capitole à Rome ont été restaurées en 2010.

Figure 30

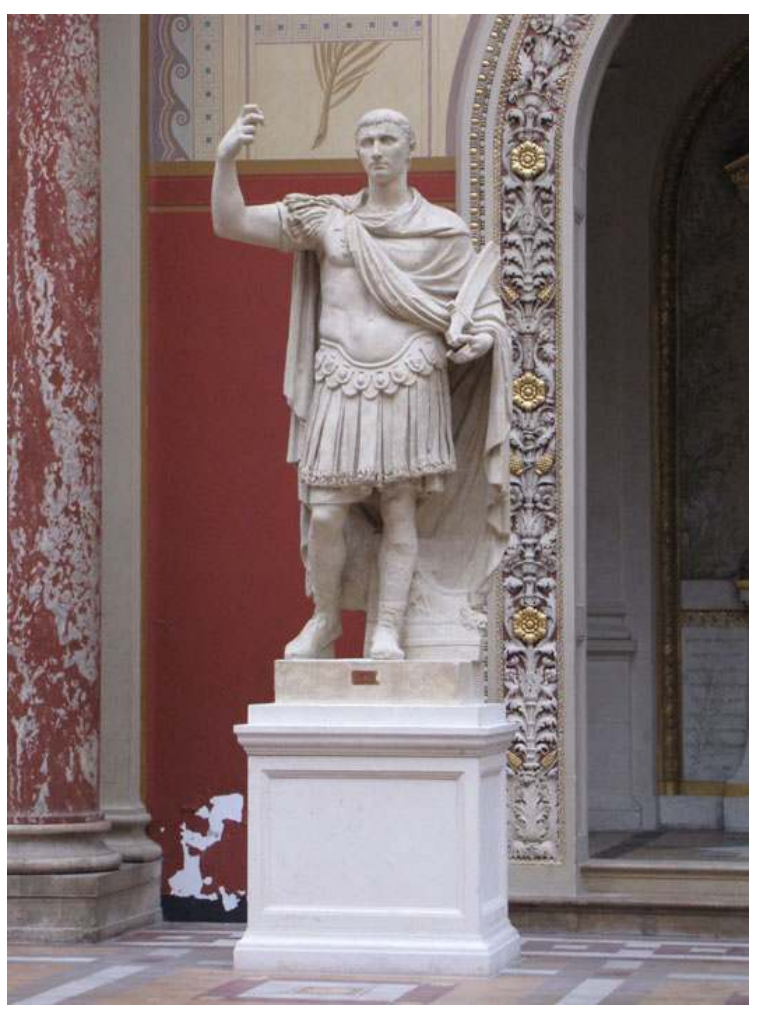

Le tirage d'une statue de navarque dit Auguste après sa restauration. Cour vitrée du palais des études de l'École nationale supérieure des beaux-arts de Paris.

Phot. Joudrier, A., 2013. @ Musée du Louvre. 
Figure 31

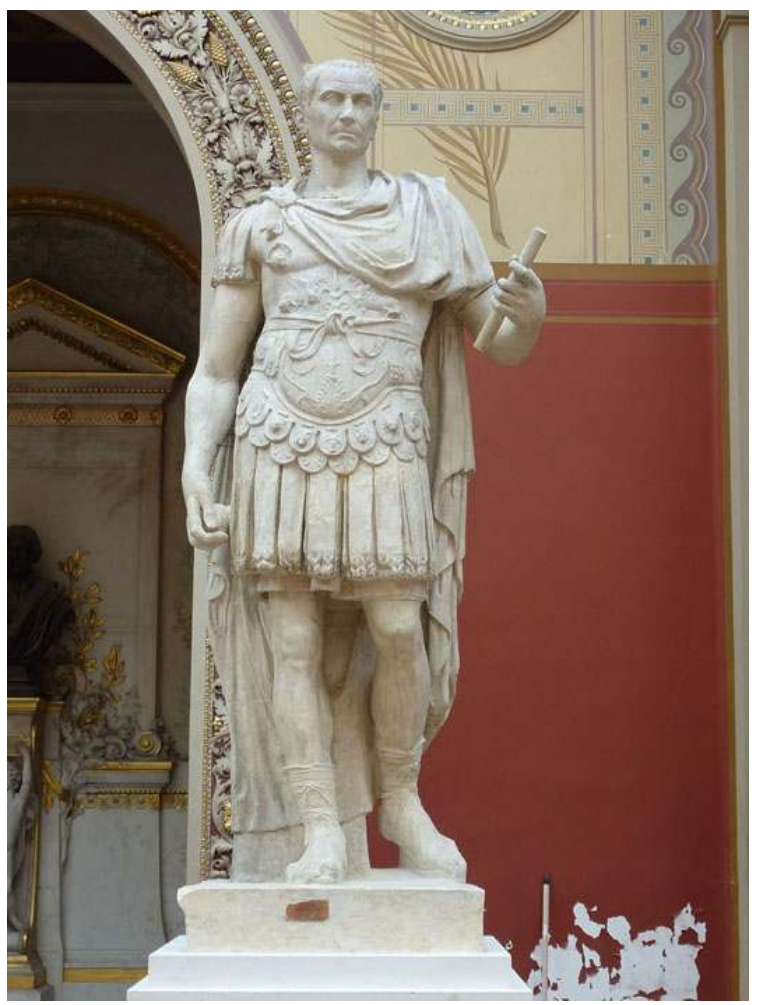

Le tirage d'une statue dite César après sa restauration. Cour vitrée du palais des Études de l'École nationale supérieure des beaux-arts de Paris.

Phot. Joudrier, A., 2013. (c) Musée du Louvre.

Les caractéristiques que l'on peut relever sur ces deux pièces concernant la technique, le tirage et la constitution du plâtre sont similaires à celles vues précédemment : moule à pièces, vraisemblablement en terre, laissant des empreintes en surface, un réseau de coutures, et des décalages de pièces comparables à celles des tirages anciens (fig. 32). Ils sont l'un et l'autre très denses (691 kg et $697 \mathrm{~kg}$ ), et d'une porosité importante. 
Figure 32

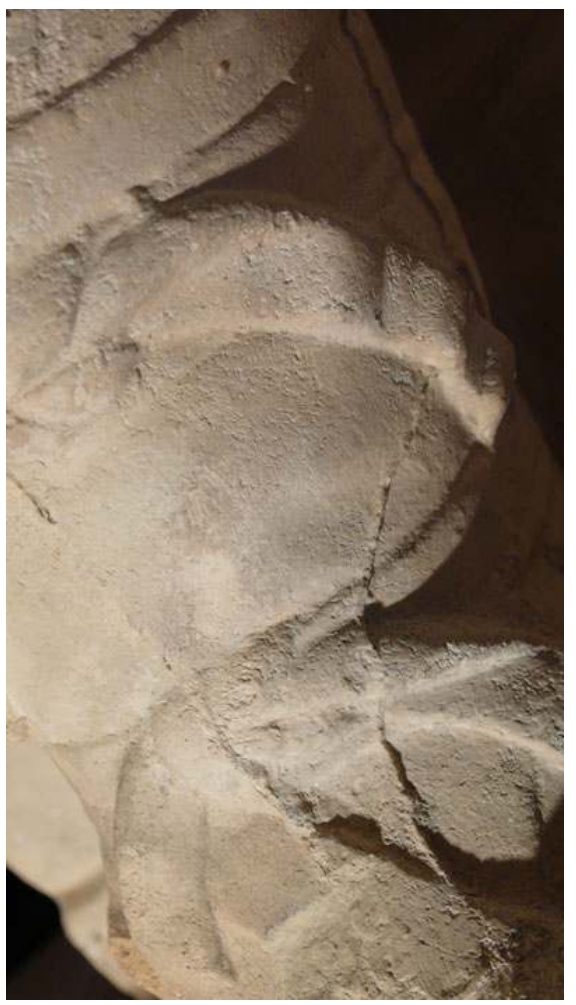

Le tirage d'une statue de navarque dit Auguste après sa restauration. Détail de coutures et d'une empreinte de pièce de petites dimensions avec un angle pointu.

Phot. Quatreveau, A., 2010. (c) Musée du Louvre.

51 La terrasse d'Auguste est pleine, comblée avec des briques de terre cuite que l'on aperçoit par une lacune latérale et il est armé de fers de section carrée qui renforcent l'arrière du mollet droit, et de fil de fer visible dans les doigts des mains.

52 Sans doute pour harmoniser différentes interventions de restauration comme des fractures ou des bouchages, les deux tirages ont reçu des couches de badigeon très épais, ocre jaune, non huileux (fig. 33). Ils empêchent une lecture convenable du matériau mais nous reconnaissons suffisamment d'éléments permettant d'y reconnaître les caractéristiques des plâtres anciens. 
Figure 33

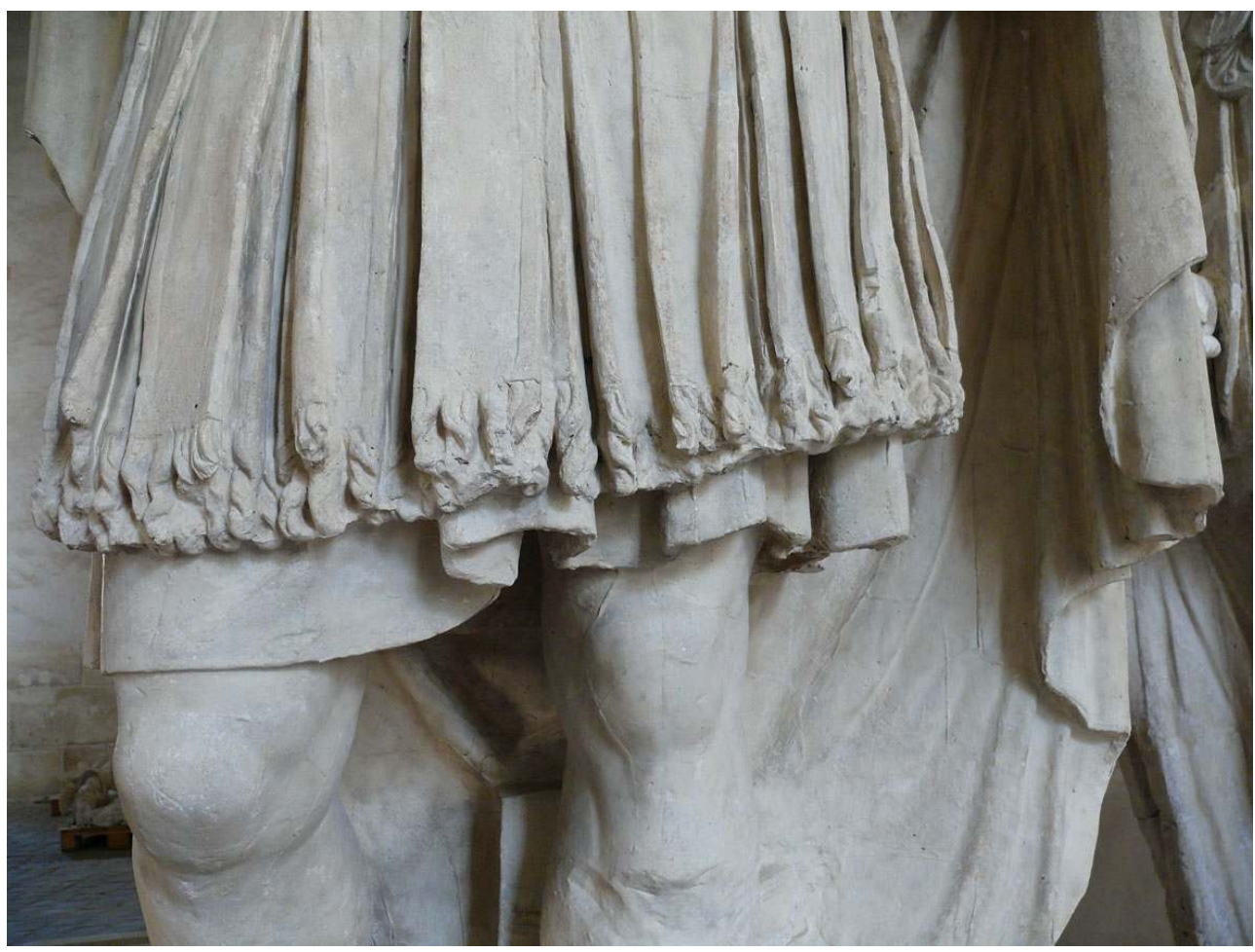

Le tirage d'une statue de navarque dit Auguste après sa restauration. Détail avec les badigeons.

Phot. Quatreveau, A., 2010. (c) Musée du Louvre.

53 L'un et l'autre, Auguste et César, sont évoqués dans la salle des Antiques en 1787 comme « moulés autrefois à grands frais à Rome, par ordre de Louis XIV ${ }^{23}$; ils quittent le Louvre pour être « déposés au musée des Petits-Augustins en exécution du décret du $118^{\text {bre }} 1801$ ${ }^{24}$ ». César est copié en marbre par Ambrogio Parisi entre 1688 et $1694^{25}$.

Nous pensons être en présence de tirages $\mathrm{du} \mathrm{XVII}^{\mathrm{e}}$ siècle, au moins pour une grande partie, car César provoqua la surprise en offrant à voir, exclusivement sur la tête, un réseau de coutures très fines, nettes, aux crêtes acérées (fig. 34). Ce type de réseau est indiscutablement plus récent et nous amène à admettre combien nous devons rester humbles car nous sommes en présence d'un tirage qui n'est pas intégralement ancien; des parties ont été réparées, voire refaites, et la tête a été ni plus, ni moins, changée.

Ces deux œuvres viennent d'être mises en dépôt par le musée du Louvre à l'École nationale supérieure des beaux-arts de Paris. Elles rejoignent ainsi la Cour vitrée du palais des Études de Duban qu'elles avaient quittée en 1970. 
Figure 34

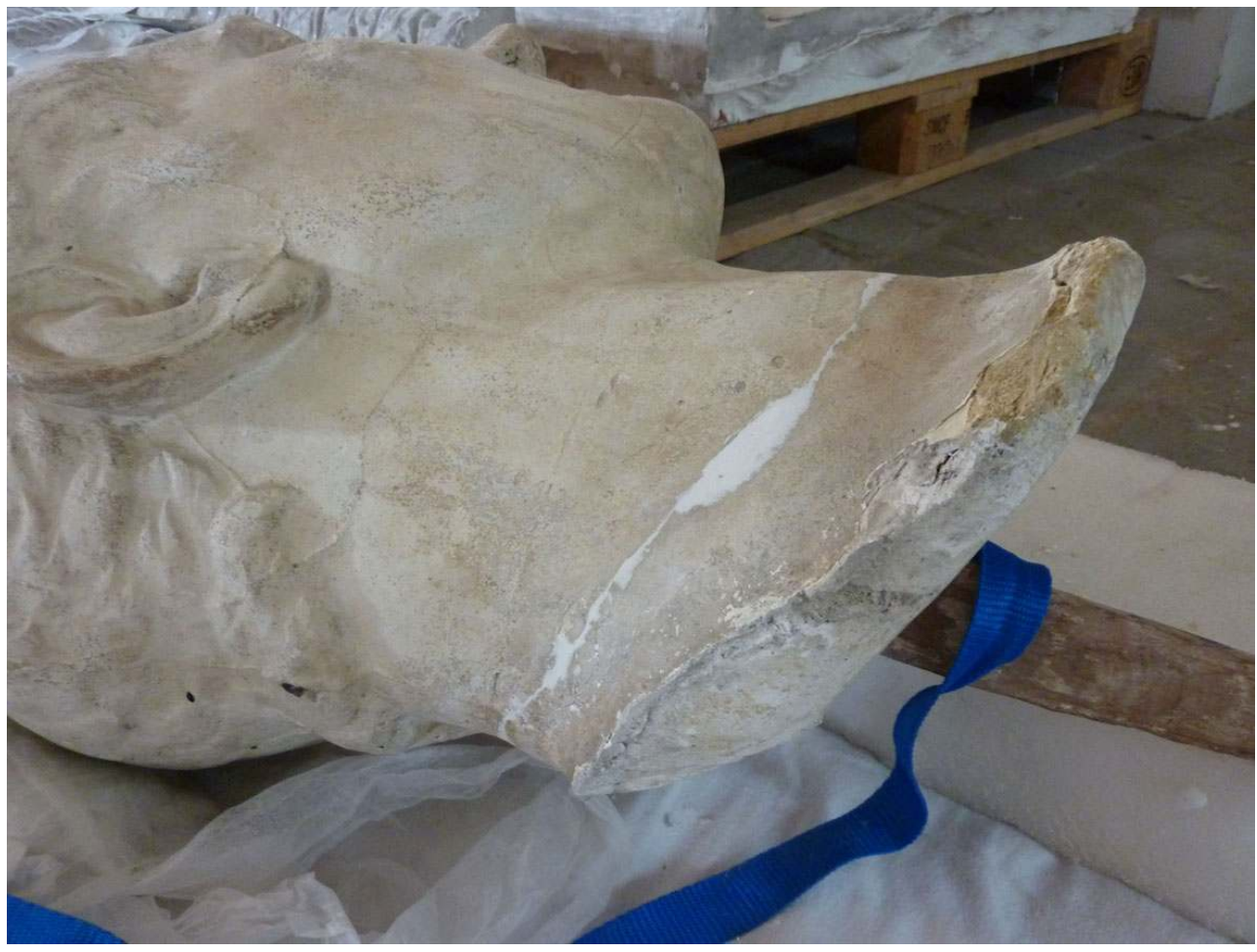

Le tirage d'une statue de navarque dit Auguste après sa restauration. Détail de la tête avec le réseau de coutures très fin et net.

Phot. Quatreveau, A., 2010. (c) Musée du Louvre.

\section{Les deux esclaves : Tigrane et Tiridate}

Des tirages en plâtre de Tigrane et de Tiridate (fig. 35), encore nommés les Esclaves ou les Prisonniers Farnèse, dont les originaux sont au musée archéologique de Naples, seul le premier a été restauré ${ }^{26}$. 
Figure 35

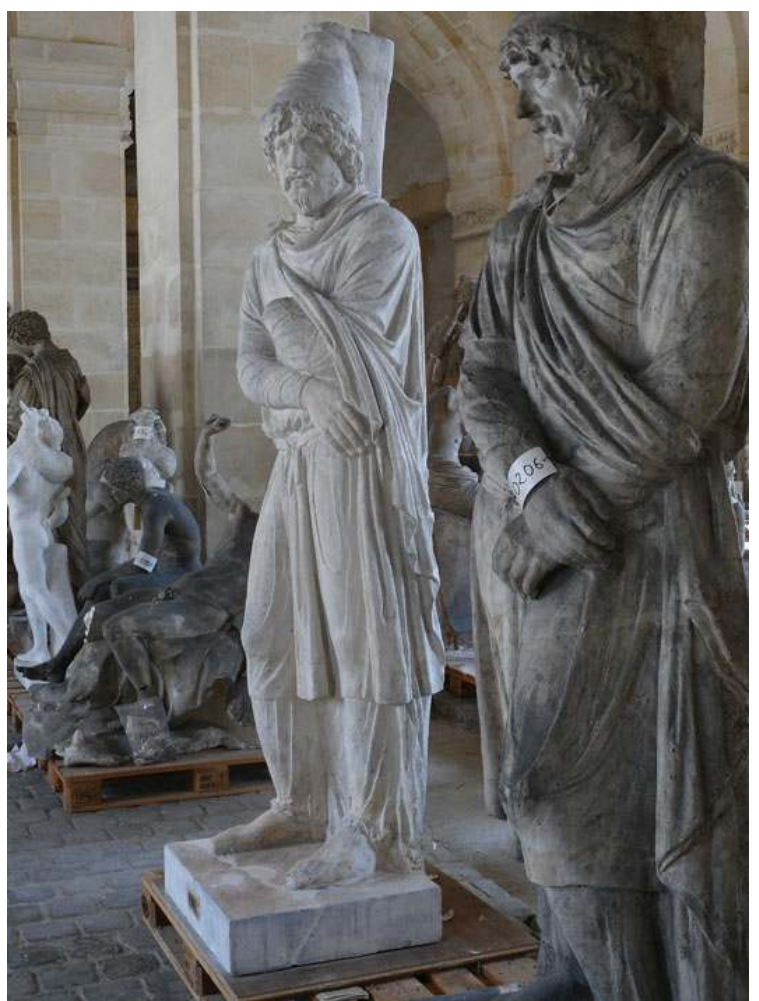

Les tirages de Tigrane (à gauche) et Tiridate (à droite).

Phot. Quatreveau, A., 2012. (c) Musée du Louvre.

La carte d'identité des tirages du XVII ${ }^{\mathrm{e}}$ siècle avec laquelle nous nous sommes peu à peu familiarisés, a été facile à dresser ; tout le faisceau des éléments attendus se trouvait présent, tant au niveau des empreintes de surface (type de coutures, légers affaissements...) (fig. 36, fig. 37) qu'à celui de la matière qui le constitue (densité, bulles, cristaux de gypse incuit et restes de charbon). 


\section{Figure 36}

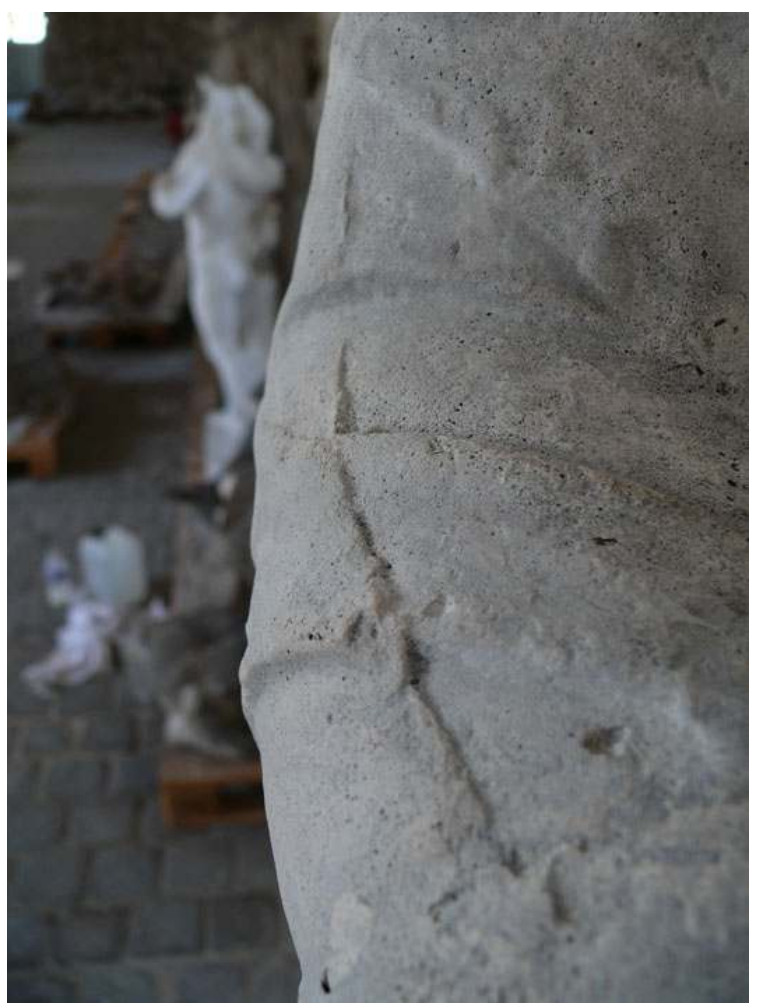

Le tirage de Tigrane. Détail au niveau de l'épaule de coutures avec un décalage de pièce. Phot. Quatreveau, A., 2012. (c) Musée du Louvre. 
Figure 37

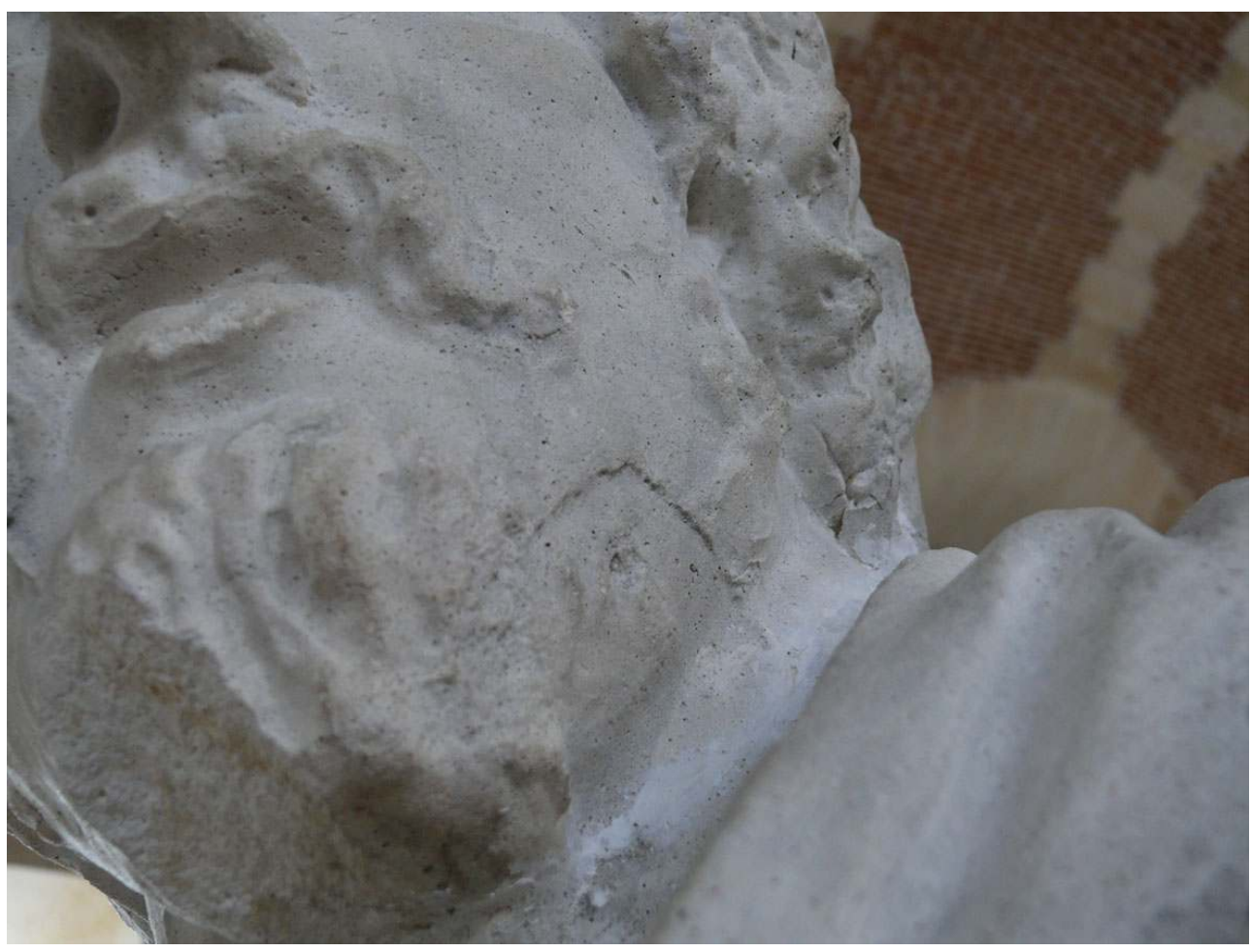

Le tirage de Tigrane. Détail au niveau du visage de coutures avec un décalage de pièce.

Phot. Quatreveau, A., 2012. (c) Musée du Louvre.

58 Le comblement de la terrasse a été réalisé avec un matériau plus grossier et des cales en planches de résineux placées dans un plâtre encore frais. Exécutée hâtivement, cette étape a créé des espaces vides entre l'empreinte et le comblement, et est à l'origine des désordres structurels qui ont affecté l'œuvre ; la terrasse s'est trouvée éclatée, obligeant Tigrane à rester couché longtemps.

L'on peut ajouter qu'il s'agit bien d'un tirage et non d'un surtirage : aucun double réseau de coutures n'a pu être relevé; il n'a pas non plus servi de modèle de mise au point, aucune croix n'est visible (fig. 38). 
Figure 38

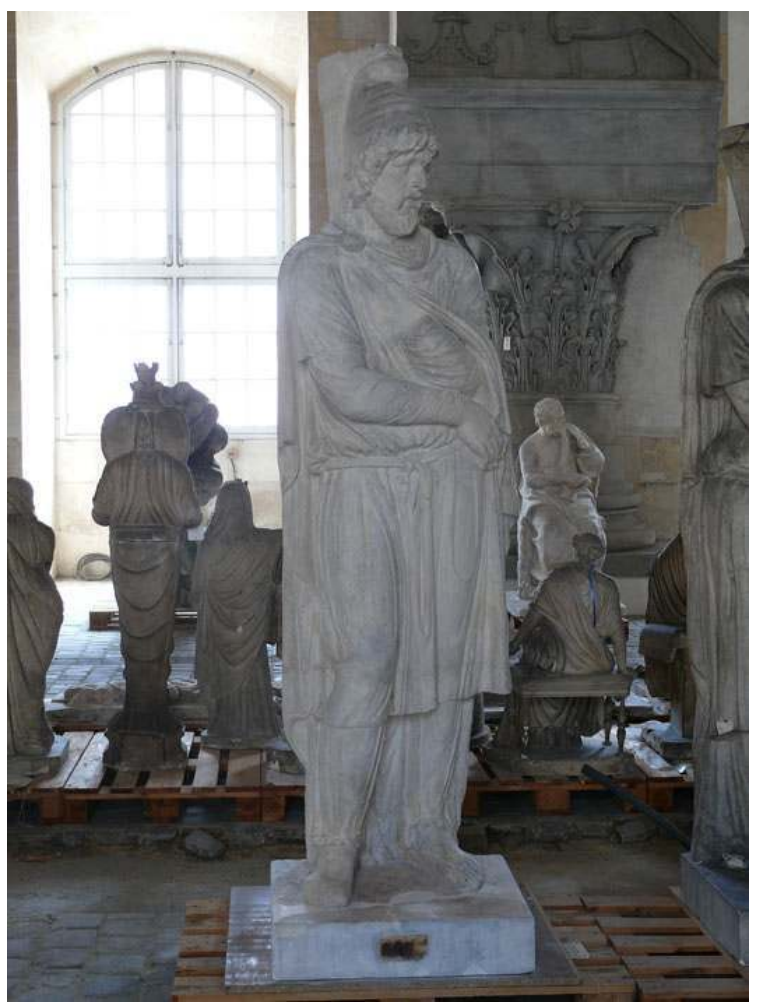

Le tirage de Tigrane restauré.

Phot. Quatreveau, A., 2012. (c) Musée du Louvre.

Tiridate $^{27}$ n'est pas encore restauré. Sa restauration est prévue pour 2014. Il présente néanmoins un aspect de surface tout à fait comparable à celui de Tigrane et une masse similaire.

61 L'un et l'autre figurent sous le nom de «deux esclaves» dans l'«État des objets appartenans à l'École royale des beaux-arts qui ont été déposés au musée des PetitsAugustins en exécution du décret du $118^{\text {bre }} 1801$ qui transfère des Écoles des arts du Louvre au cy-devant collège des Quatre-Nations $»^{28}$.

62 Ils ont été copiés en marbre, exécutés en France par Mattieu Lespagnandelle et Antoine André pour orner la rampe du Midi du parterre de Latone dans les jardins de Versailles; ils y ont été installés à partir de 1687.

\section{Une restauration prometteuse : la Gauloise morte}

Le tirage de la Gauloise morte du Groupe Ludovisi ${ }^{29}$ du Musée national romain, palais Altemps, semble aussi pouvoir rejoindre ce groupe du xvII ${ }^{e}$ siècle (fig. 39); tous les critères techniques d'attribution à cette période sont présents. Mais seule sa restauration permettra de confirmer la datation et d'éclaircir son histoire. Connu sous le nom de Petus et aria, ce groupe est exposé dans les jardins de Versailles, sculpté par François Lespingola, commencé en 1684 et terminé en 1688. 
Figure 39

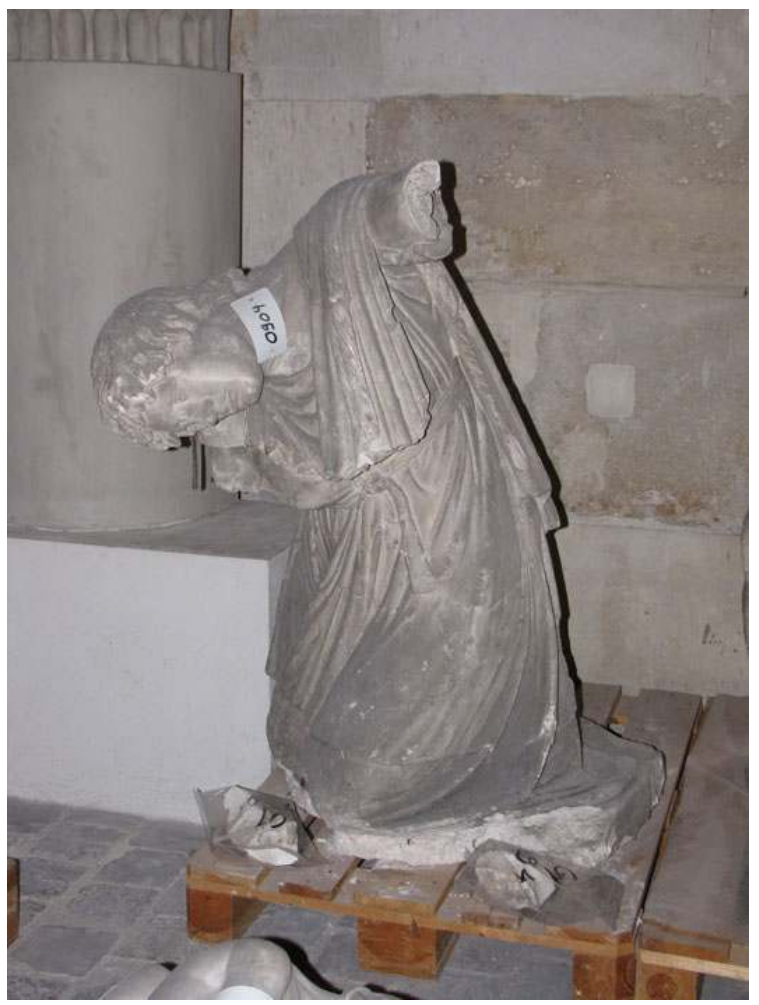

Le tirage de Gauloise morte du Groupe Ludovisi.

Phot. Le Breton, É., 2012. @ Musée du Louvre.

\section{Une surprise avec l'Ariane endormie}

Pour ces deux œuvres qui ne sont pas encore restaurées, nous devons rester extrêmement vigilants et attendre les résultats des travaux pour être formels dans la datation, car si l'on s'en tient à un état de surface, l'on peut avoir des surprises.

Ce fut le cas, par exemple, avec le tirage de l'Ariane endormie ${ }^{30}$ (fig. 40) dont le marbre est dans les musées du Vatican, et dont le modèle, qu'on appelait alors Cléopâtre, fut prisé très tôt dans le temps. Le Primatice, en 1540, la fit mouler dans le jardin du Belvédère. Le tirage de la gypsothèque n'est pas encore restauré. Par son aspect, il est vrai sur certaines zones seulement, on pouvait penser qu'elle eût pu être du XVII ${ }^{\mathrm{e}}$ ou XVIII ${ }^{\mathrm{e}}$ siècle. Les autres zones, plus récentes manifestement, pouvaient laisser imaginer des interventions de remaniements et/ou réparations. C'est une estampille de l'atelier de Leopoldo Malpieri (mouleur romain $\mathrm{du} \mathrm{xIX}^{\mathrm{e}}$ siècle), clairement lisible, qui nous obligea à renoncer à l'ancienneté... Mais ces estampilles, si précieux indicateurs, sont très rares, et le plus souvent, on doit s'en passer. 
Figure 40

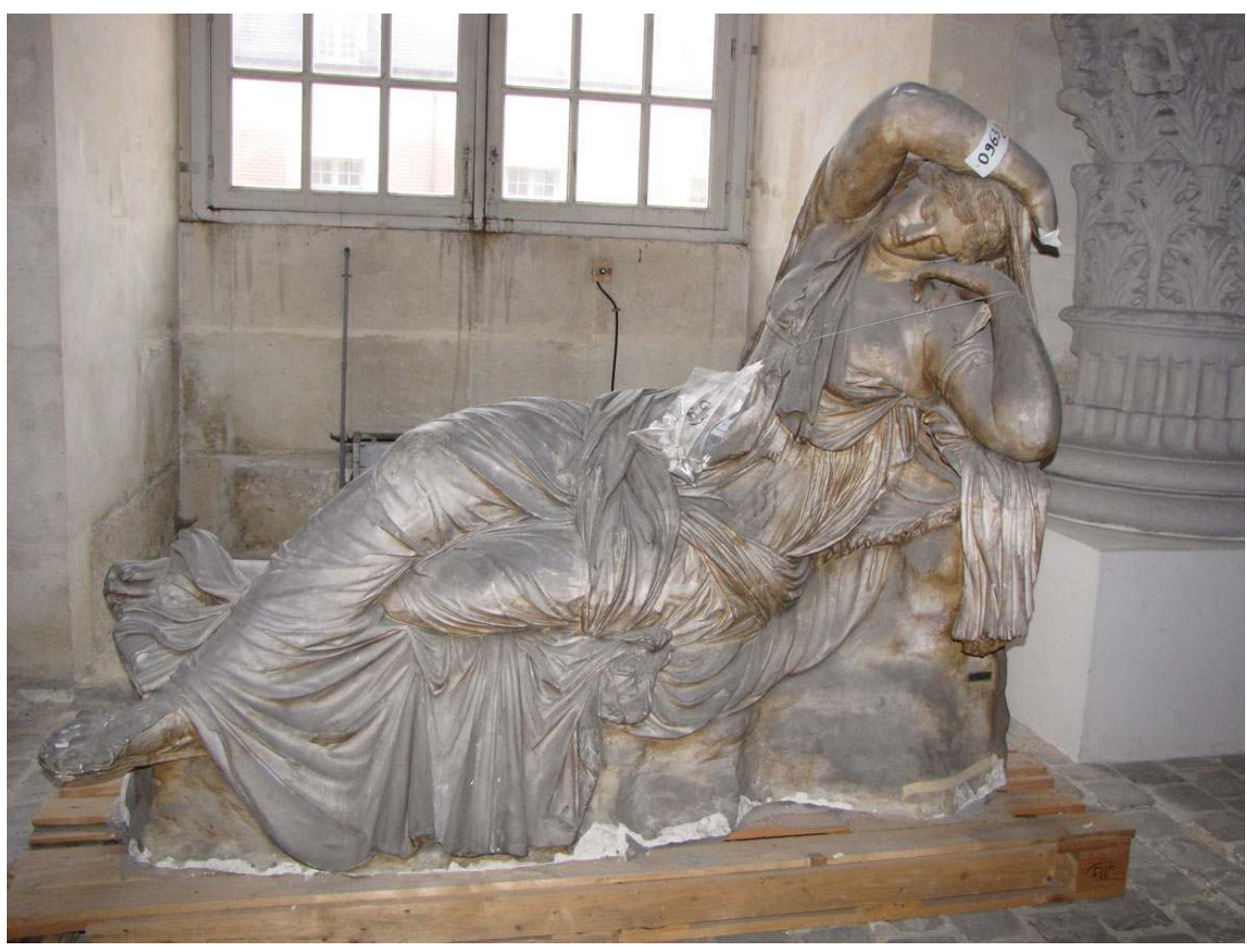

Le tirage d'Ariane endormie.

Phot. Joudrier, A., 2012. (c) Musée du Louvre.

Ce panorama, brossé très rapidement, ne reflète, nous le pensons, qu'un état encore partiel du sujet de la datation des tirages en plâtre. Mais il n'empêche que, même si bien des interrogations demeurent, nous parvenons aujourd'hui, pour cette période du XVII siècle, à élaborer une grille de lecture suivie d'une carte d'identité pour éclairer des histoires de manière assez significative.

De 2004 à 2012, 91 œuvres ont été restaurées ; six sont clairement datées du XVII ${ }^{e}$ siècle, et deux sont donc fortement présumées appartenir à cette époque. Il est possible que la liste ne soit pas exhaustive mais d'ores et déjà, l'ensemble constitue un cas tout à fait unique. D'autre part, ces travaux nous permettent d'imaginer la possibilité de dresser d'autres cartes d'identité complètes, afin d'éclairer d'autres périodes.

En effet, les campagnes de restauration dans lesquelles le musée du Louvre s'est engagé sont encore loin d'être achevées et leur poursuite s'annonce très prometteuse.

Nous tenons à saluer le travail de restauration remarquable réalisé par Pascale Roumégoux et Anthony Quatreveau, notamment sur les œuvres les plus gravement endommagées structurellement, celles aussi de ce fait, qui nous ont apporté, grâce à leur approche et leur talent, les plus précieux renseignements.

Biographie

Élisabeth Le Breton est à la conservation des œuvres du musée du Louvre depuis 1988. Ingénieur d'études au département des Antiquités grecques, étrusques et romaines du musée du Louvre, elle gère la collection de moulages d'antiques conservés dans la gypsothèque du Louvre dans les Écuries du roi à Versailles. 


\section{BIBLIOGRAPHIE}

DEZALLIER D'ARGENVILLE, Antoine-Nicolas. Description sommaire des ouvrages de peinture, sculpture et gravure exposés dans les salles de l'Académie royale. Paris : Debure père, 1781.

HASKELL, Francis, PENNY, Nicholas. Pour l'amour de l'antique. La statuaire gréco-romaine et le goût européen, 1500-1900 (trad. fr.). Paris : Hachette, 1988.

MARTINEZ, Jean-Luc. « Les moulages en plâtre d'après l'antique du musée du Louvre : une utopie du XIX ${ }^{\mathrm{e}}$ siècle ». Dans PASQUIER, Alain, GABORIT, Jean-René, CUZIN, Jean-Pierre. D'après l'antique. (cat. exp., Paris, musée du Louvre, 16 octobre 2000-15 janvier 2001). Paris : Réunion des musées nationaux, 2000, p. 78-82.

MONTAIGLON, Anatole de. Procès-verbaux de l'Académie royale de peinture et de sculpture (1648-1792), publiés pour la Société de l'histoire de l'art français d'après les registres originaux conservés à l'École des beaux-arts. Paris : J. Baur, 1875-1892, T I (1648-1672).

PINATEL, Christiane. « Les envois de moulages d'antiques par l'Académie de France à Rome à l'adresse de l'École des beaux-arts ». Dans LAVAGNE, Henri, QUEYREL, François (éd.). Les moulages de sculptures antiques et l'histoire de l'archéologie. (Actes du colloque international, Paris, 24 octobre 1997). Genève : Droz, 2000, p. 75-120.

PINATEL, Christiane. «"L’Hercule Farnèse" : la version de Jean Cornu pour les jardins de Versailles ». Versalia, Revue de la société des amis de Versailles, n 3, 2000, p. 140-151.

PINCAS, Stéphane. Un jardin à la française. Paris : Éditions de La Martinière, 2001.

THIÉRY, Luc-Vincent. Guide des amateurs et des étrangers voyageurs à Paris. Paris : Hardouin et Gattey, 1787. Vol. I.

\section{NOTES}

1. - Nous préfèrerons le terme de tirage ou encore, de jet ou de forme, pour l'objet en plâtre obtenu par la technique du moulage. Le terme de «moulage » souvent employé indifféremment pour la technique et pour l'objet, prête trop à confusion.

2. - Ces collections proviennent de l'École des beaux-arts de Paris, héritière des collections royales et de celles de l'Académie royale de peinture et de sculpture, de l'université de la Sorbonne/Institut d'art et d'archéologie, et du musée du Louvre

3. - Affectation par arrêté ministériel daté de décembre 2001 au profit du département des Antiquités grecques, étrusques et romaines du musée du Louvre; parution au Bulletin Officiel Hors-série $n^{\circ} 1$ de septembre 2002.

4. - Le surmoulage est une technique qui consiste à réaliser une prise d'empreinte, non pas sur une œuvre originale, mais sur un tirage préalablement exécuté.

5. - Ms $35 n^{\circ} 25$ - 26 avril 1710. Noté « manque suivant le récolement du 23 nov. 1737 ». Ms 35 «Inventaire des ouvrages des sculptures en plastre appartenant à l'Académie Royale de Peinture et Sculpture moulez sur l'antique et données par le Roi », Bibliothèque de l'École nationale supérieure des beaux-Arts. Inventaire non daté, la première date citée est le 27 février 1666. 
6. - Gy 0249 : H. 100, L. 190, P. 89. Restauration de Pascale Roumégoux en 2004/2005. Les numéros précédés de « Gy » sont les numéros d'inventaire de la collection de tirages en plâtre du musée du Louvre.

7. - L'expression " gâcher clair » s'entend par opposition à "gâcher serré ». L'on gâche « serré » en augmentant la quantité de poudre par rapport à l'eau afin d'obtenir un plâtre consistant ou épais, et l'on gâche clair en mettant moins de poudre dans cette même quantité d'eau pour obtenir un plâtre plus liquide ou fluide.

8. - Michel Monier séjourne à Rome entre 1671 et 1682.

9. - Gy 1300 : H. 326, L. 160, P. 112. Restauration de Pascale Roumégoux.

10. - Nous appelons « surtirage » un tirage obtenu par la technique du surmoulage.

11. - PINATEL, C. «Les envois de moulages d'antiques à l'école des Beaux-Arts de Paris par l'Académie de France à Rome ». Dans Les moulages de sculptures antiques et l'histoire de l'archéologie. Actes du colloque international, Paris, 24 octobre 1997, édité par H. Lavagne et F. Queyrel. Genève : Droz, 2000. PINATEL, C. «L'Hercule Farnèse : La version de Jean Cornu pour les jardins de Versailles ", Versalia, Revue de la société des amis de Versailles, n³, 2000, p. 140-152.

12. - THIÉRY, Luc-Vincent. Guide des amateurs et des étrangers voyageurs à Paris. Paris : Hardouin et Gattey, 1787. Vol. I.

13. - Ms $35 . n^{\circ}$ « $1 »-27$ février 1666 . Voir note 5.

14. - L'arrêté de 1666 est repris en janvier 1667.

15. - AN AJ/52/453 - $1^{\mathrm{er}}$ juin 1817. "État des objets [...] qui ont été déposés au musée des PetitsAugustins en exécution du décret du 11 8bre 1801 qui transfère des Écoles des arts du Louvre au cy-devant collège des Quatre-Nations ».

16. - Gy 0247 : H. 220, L. 94, P. 60. Restauration de Pascale Roumégoux.

17. - THIÉRY, Luc-Vincent, op. cit., p. 337.

18. - Ms $35 . n^{\circ} 30-26$ avril 1710 . Voir note 5.

19. - $\mathrm{N}^{\circ}$ d'inventaire Louvre RF 199. H. : 0,75 m. ; L. : 0,33 m. ; Pr. : 0,20 m.

20. - AN AJ/52/ $453-1^{\text {er }}$ juin 1817.

21. - Gy 0198 - un navarque dit «Auguste »: H. 286, L. 140, P. 95. Restauration d'Anthony Quatreveau.

22. - Gy 0199 - une statue probablement du temps de Trajan dite «César » : H. 294, L. 119, P. 79. Restauration de Pascale Roumégoux.

23. - THIÉRY, Luc-Vincent, op. cit., p. 336.

24. - AN AJ/52/ $453-1^{\text {er }}$ juin 1817.

25. - Il sera installé en 1800 dans le jardin des Tuileries.

26. - Gy 0208 : H. 254, L. 69, P. 45. Restauration d'Anthony Quatreveau en 2012.

27. - Gy 0206 : H. 233, L. 71, P. 60.

28. - AN AJ/52/ $453-1^{\text {er }}$ juin 1817.

29. - Gy 0904 : H. 124, L. 91, P. 111.

30. - Gy 0963 : H. 162, L. 241, P. 84.

\section{RÉSUMÉS}

Enracinée dans le $\mathrm{XVI}^{\mathrm{e}}$ siècle, la tradition qui consiste à copier l'antique à partir de modèles en plâtre s'épanouit au XVII ${ }^{\mathrm{e}}$ siècle grâce à la politique menée sous Louis XIV et se prolonge par la 
suite. La gypsothèque du musée du Louvre est née en décembre 2001 par arrêté d'affectation du ministère de la Culture, de trois grandes collections nationales provenant d'institutions parisiennes : l'École nationale supérieure des beaux-arts de Paris, l'Institut d'art et d'archéologie de la rue Michelet et le musée du Louvre. Abrités depuis 1970 dans les Écuries du roi à Versailles, près de 5000 moulages d'antiques y sont aujourd'hui dénombrés. Les modèles si prisés au XVII et au début du XVIII ${ }^{\mathrm{e}}$ siècle, à quelques exceptions, sont toujours présents dans la collection. Mais les reconnaître n'est pas déterminant : le moulage se décline à l'envi, peut être restauré à différentes reprises, puis de nouveau surmoulé ; il n'est jamais signé. Que connaît-t-on de l'histoire de ces tirages anciens, peut-on en reconnaître dans la gypsothèque et par quels moyens ? C'est ce à quoi nous allons tenter d'apporter des éléments de réponse en particulier grâce à l'apport de campagnes fondamentales de restauration, menées par le musée du Louvre depuis dix ans.

Dating back to the sixteenth century, the tradition of making copies of the statues of classical antiquity by making plaster moulds of them, developed during the seventeenth century under the reign of Louis XIV and continued thereafter. The gypsothèque of the Louvre museum was created in December 2001 by the Ministry of Culture and brought together three major public collections coming from the École nationale supérieure des Beaux Arts, the Institut d'art et d'archéologie at the rue Michelet and the Louvre itself. More than 5,000 moulds have been identified. Since 1970 they were stored at Versailles in the Écuries du Roi, the royal stables. With only a few exceptions, the models appreciated in the seventeenth and early eighteenth centuries are still kept in the collection. But identifying them is not everything. The moulds can be used for new casts as often is required; they can be restored several times; new moulds can be made from an old cast; the mould is never signed. So what can we know about the history of these old moulds, what pieces can be identified in the collection and how? This contribution hopes to offer some replies to these questions, based on information coming from the work of restoration carried out by the Louvre over the past ten years.

\section{INDEX}

Keywords : Musée du Louvre, gypsothèque, plaster casts, moulding, restoration, dating, École des beaux-arts de Paris, Institut d'art et d'archéologie, Gaulois mourant from the Capitole, Hercule Farnèse

Mots-clés : Musée du Louvre, Gypsothèque, tirages en plâtre, moulage, restauration, datation, École des beaux-arts de Paris, Institut d'art et d'archéologie, Gaulois mourant du Capitole, Hercule Farnèse

\section{AUTEUR}

\section{ÉLISABETH LE BRETON}

Ingénieur d'études au département des Antiquités grecques, étrusques et romaines, Musée du Louvre Elisabeth.Lebreton@louvre.fr 